\title{
Palladium-Catalyzed Decarbonylative Borylation of Aryl Anhydrides
}

Wenzhi Zhang, ${ }^{\dagger}$ Fusheng Bie, ${ }^{\ddagger}$ Jie Ma,${ }^{\dagger}$ Fengyan Zhou, ${ }^{\dagger}$ Michal Szostak ${ }^{*,}$ and Chengwei Liu*,

${ }^{\dagger}$ College of Chemistry, Chemical Engineering and Materials Science, Zaozhuang University, 1 Bei'an Road, Zaozhuang, Shandong 277160, China

${ }^{*}$ Shandong Lunan Coal Chemical Research Institute of Engineering and Technology, Zaozhuang University, 1 Bei'an Road, Zaozhuang, Shandong 277160, China

${ }^{\S}$ Department of Chemistry, Rutgers University, 73 Warren Street, Newark, New Jersey 07102, United States

${ }^{\#}$ School of Chemistry and Materials Science, Nanjing University of Information Science and Technology, 219 Ningliu Road, Nanjing, Jiangsu 210044, China

michal.szostak@rutgers.edu; chengwei.liu@nuist.edu.cn 


\section{Supporting Information}

\section{Table of Contents}

$1.0 \mathrm{mmol}$ scale experiment

${ }^{1} \mathrm{H}$ NMR, ${ }^{13} \mathrm{C}$ NMR and ${ }^{19} \mathrm{~F}$ NMR Spectra

SI-3

\section{Corresponding Author:}

Prof. Dr. M. Szostak

Rutgers University michal.szostak@rutgers.edu
Prof. Dr. C. Liu

Nanjing University of Information Science and Technology chengwei.liu@nuist.edu.cn

\section{0 mmol Scale Experiment}

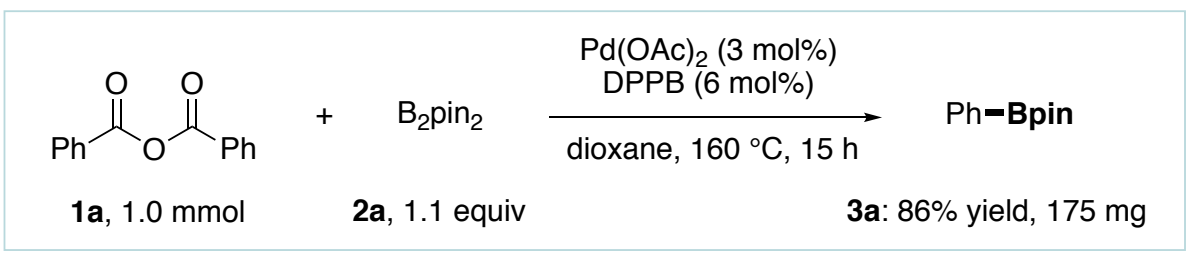


<smiles>Cc1ccc(C(=O)OC(=O)c2ccc(C)cc2)cc1</smiles>

$1 \mathrm{~b}$ $\left(500 \mathrm{MHz}, \mathrm{CDCl}_{3}\right)$
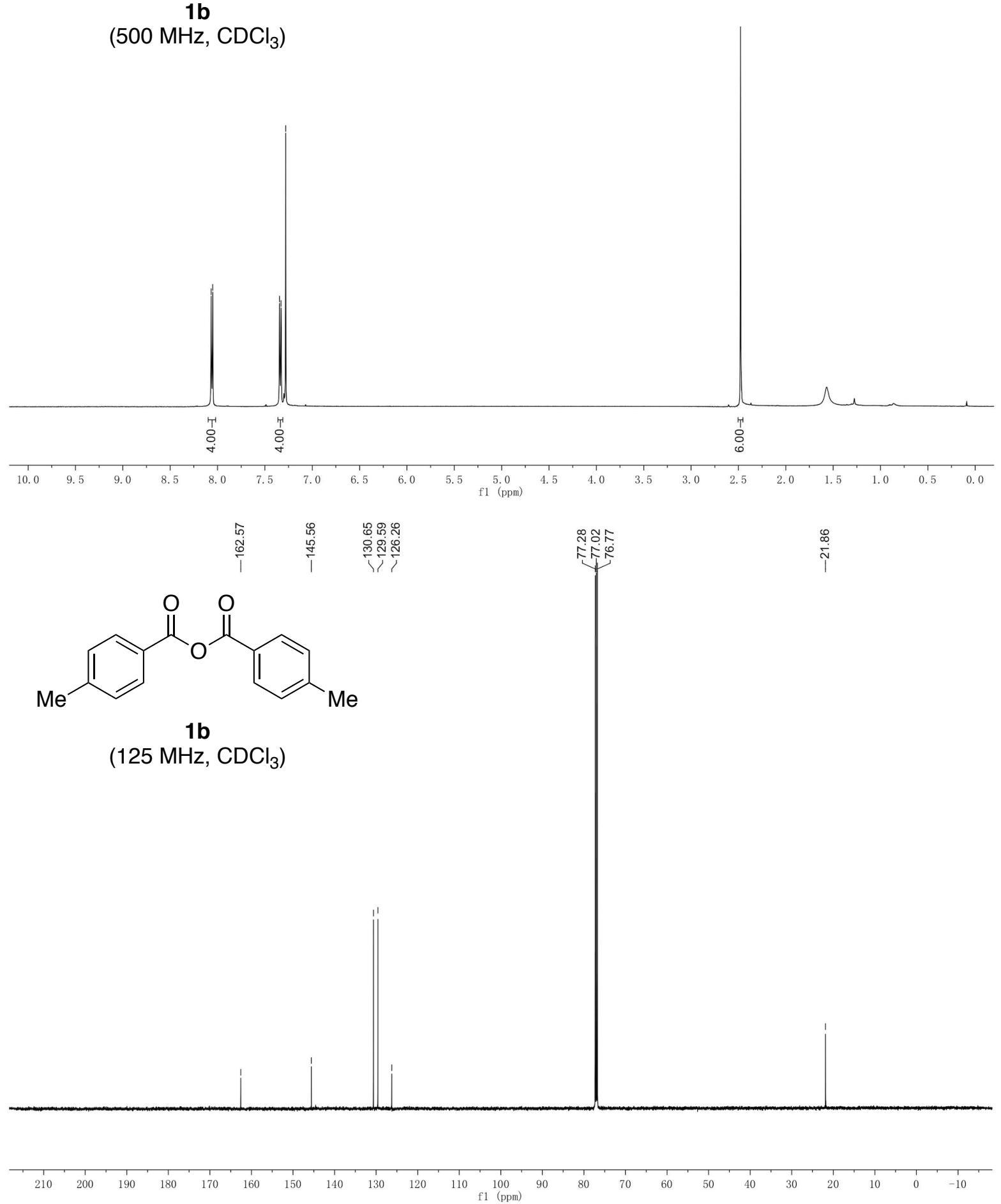

SI-3 

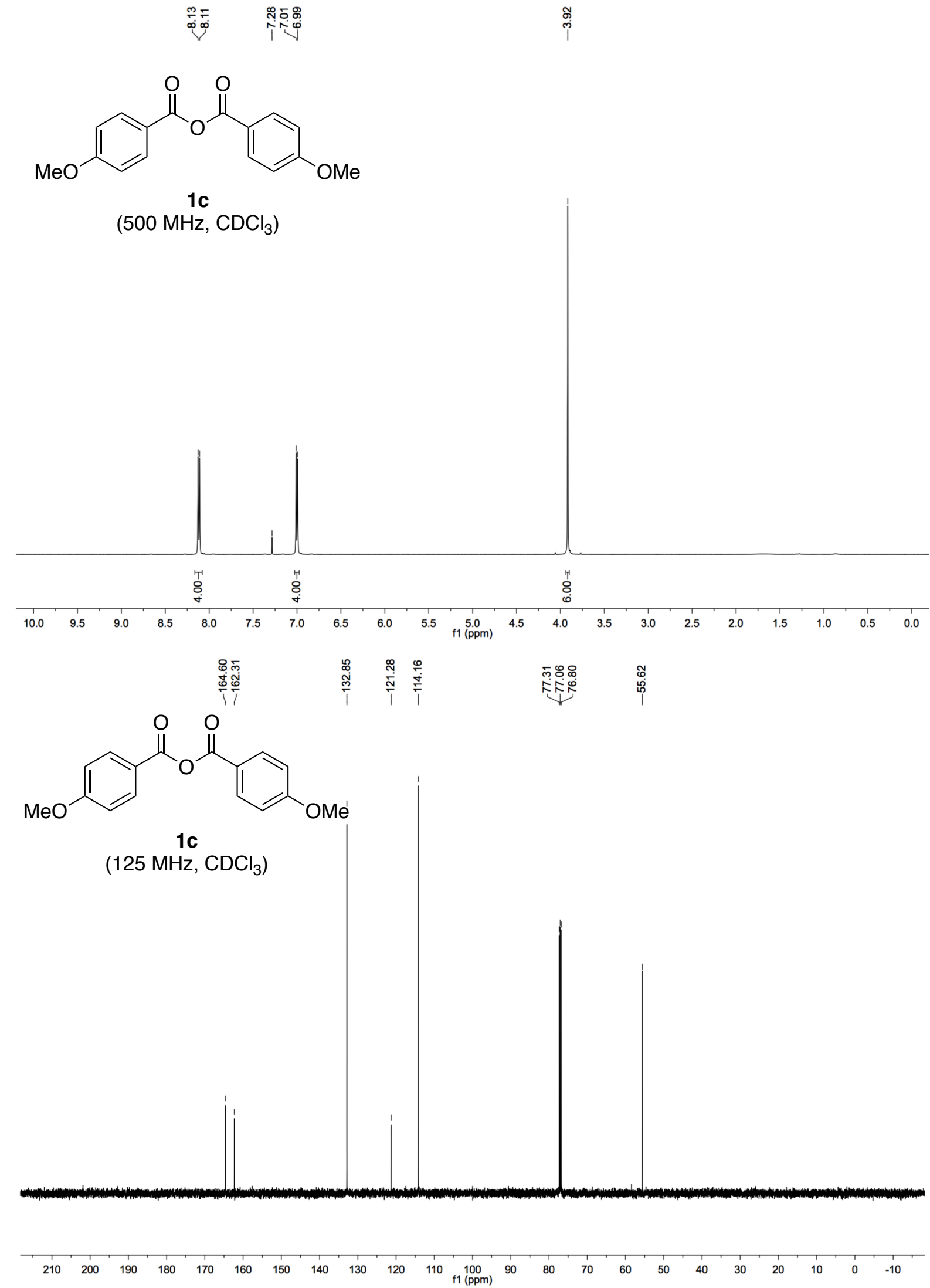

SI-4 


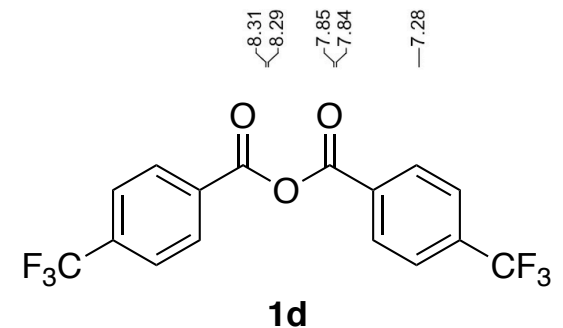

$\left(500 \mathrm{MHz}, \mathrm{CDCl}_{3}\right)$
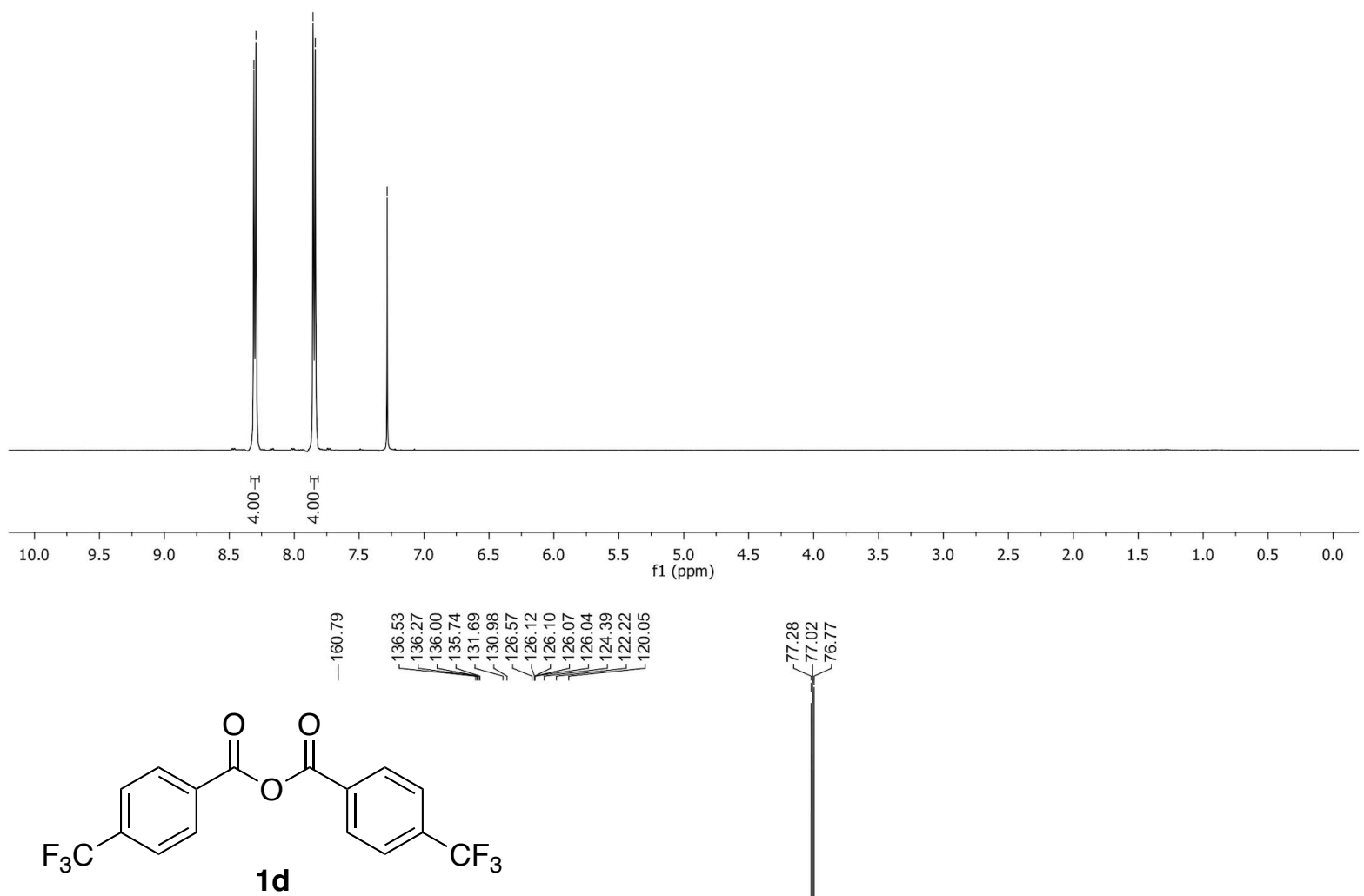

$\left(125 \mathrm{MHz} \mathrm{CDCl}_{3}\right)$

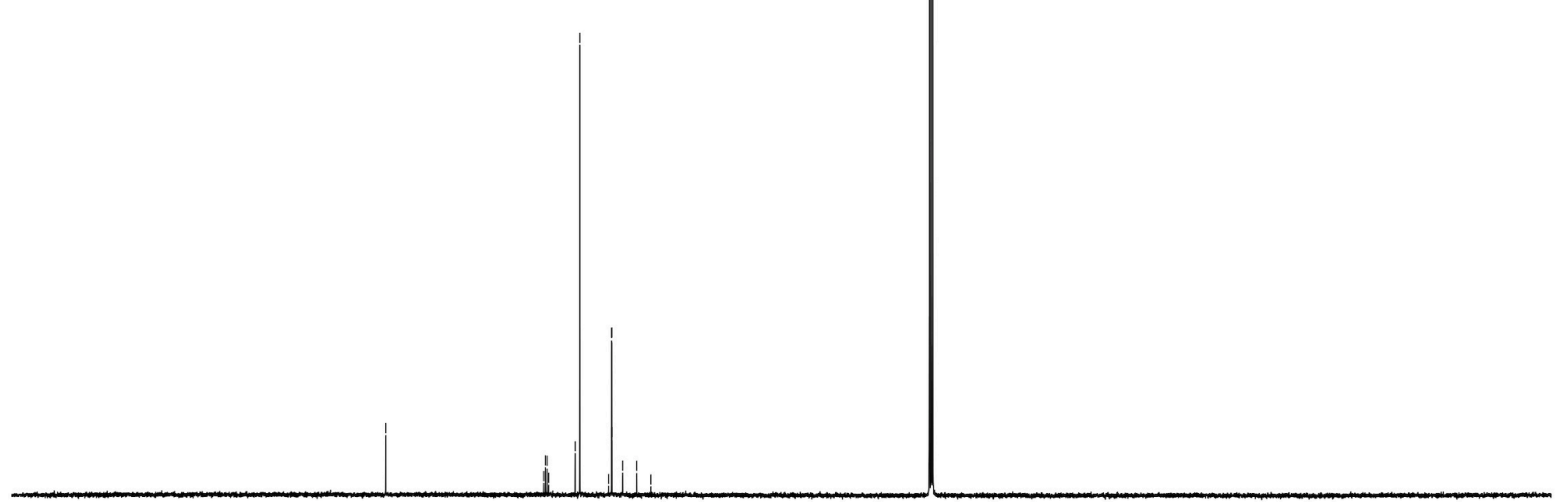

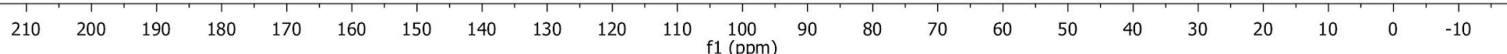

SI-5 
<smiles>COC(=O)c1ccc(C(=O)OC(=O)c2ccc(C(=O)OC)cc2)cc1</smiles>
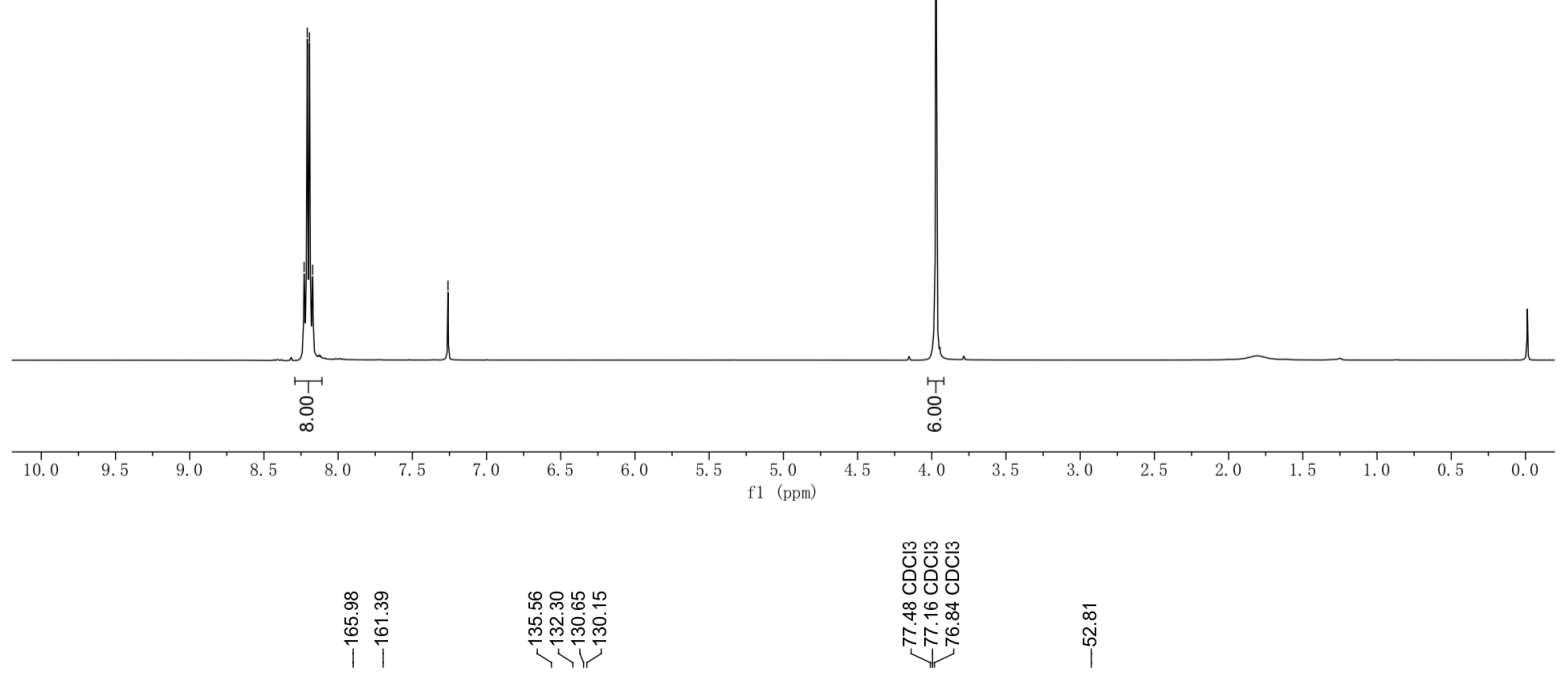<smiles>COC(=O)c1ccc(C(=O)OC(=O)c2ccc(C(=O)OC)cc2)cc1</smiles>
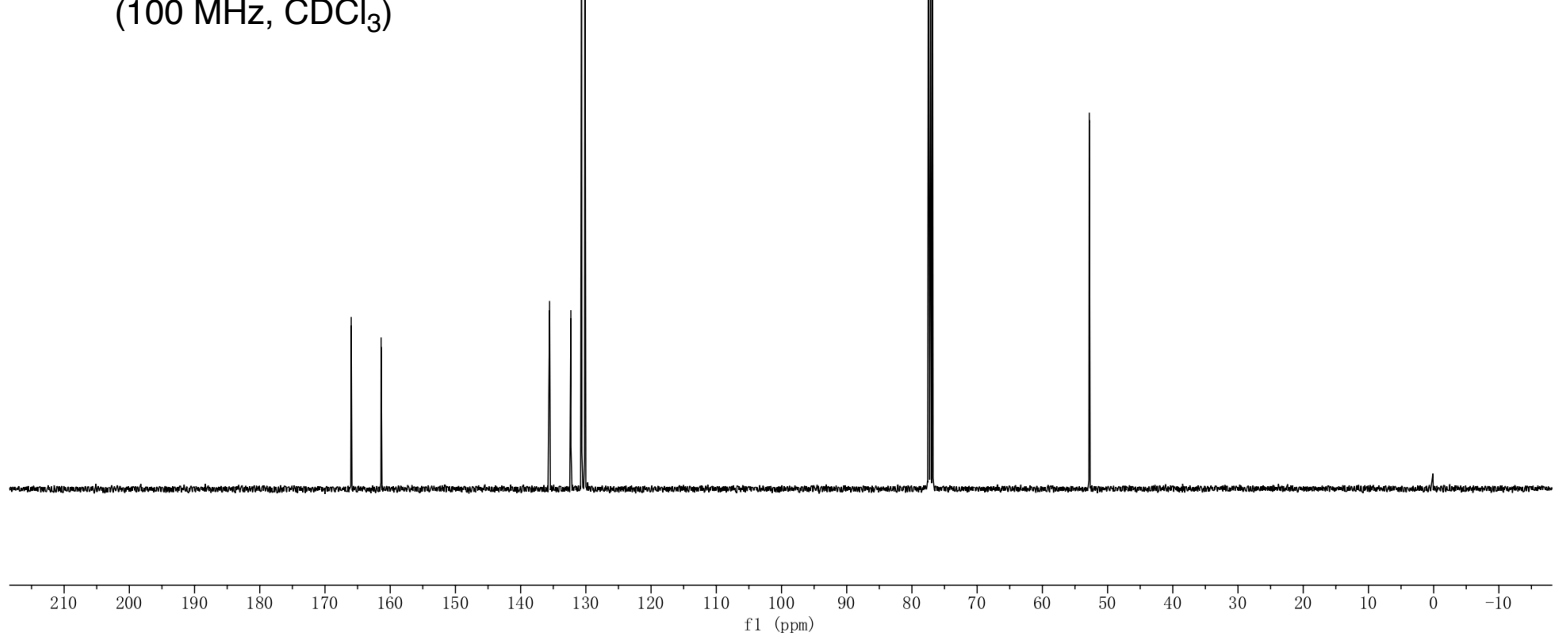
<smiles>CC(=O)c1ccc(C(=O)OC(=O)c2ccc(C(C)=O)cc2)cc1</smiles>

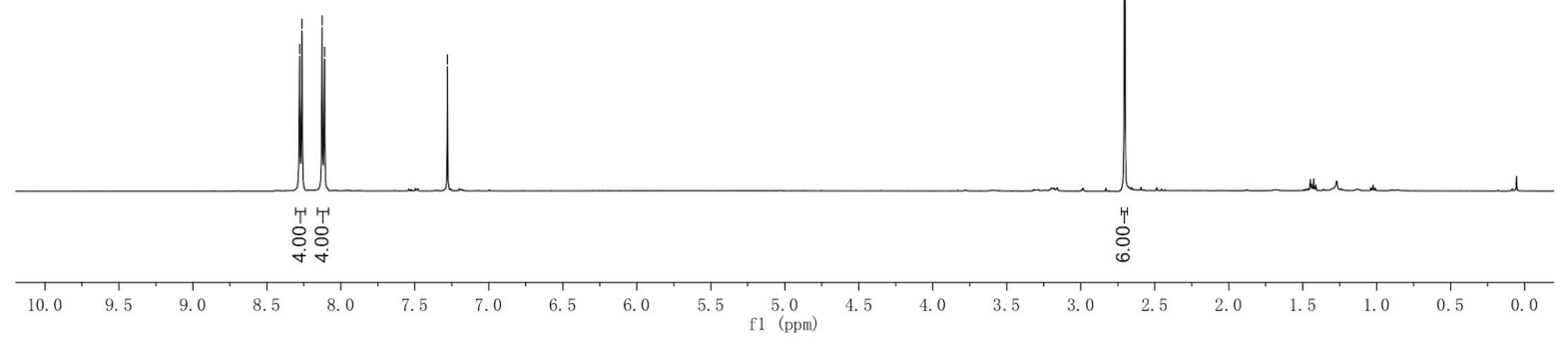<smiles>CC(=O)c1ccc(C(=O)OC(=O)c2ccc(C(C)=O)cc2)cc1</smiles>
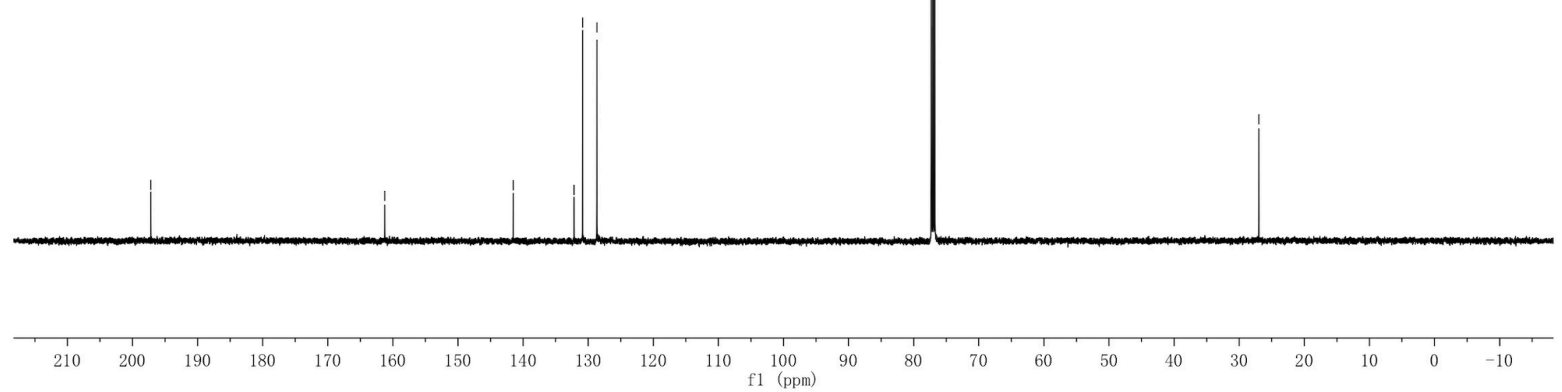

SI-7 

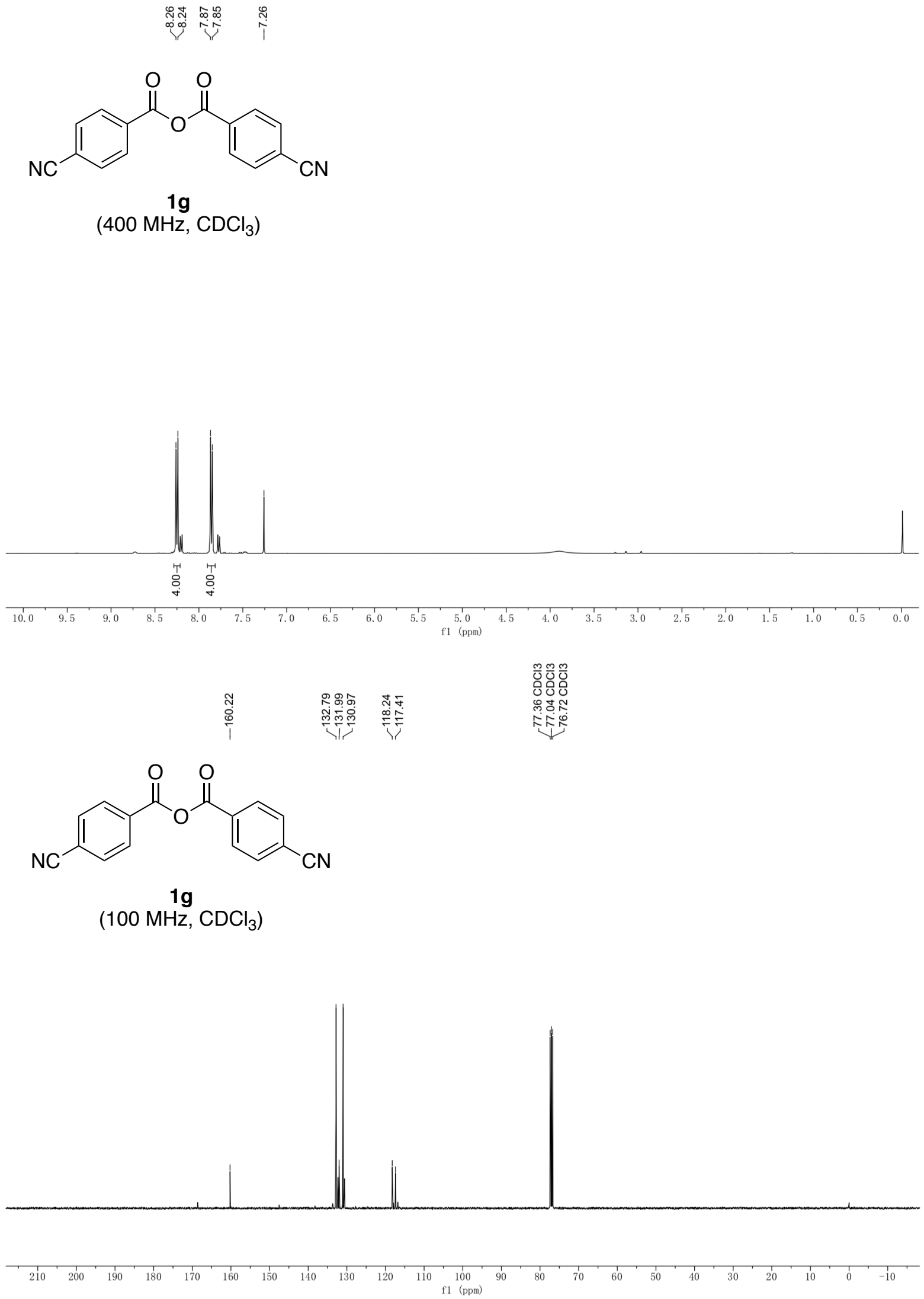

SI-8 

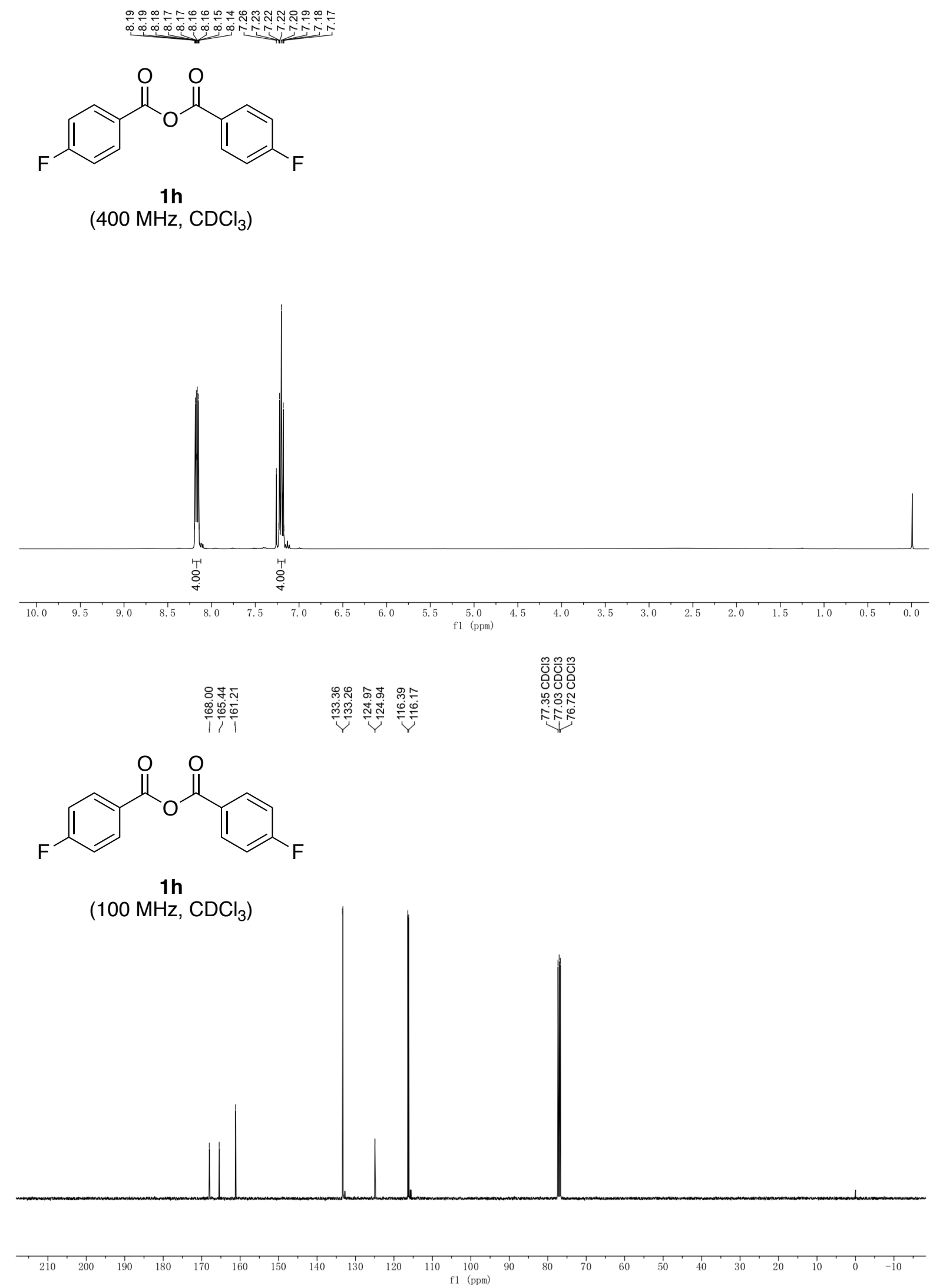
<smiles>O=C(OC(=O)c1ccc(F)cc1)c1ccc(F)cc1</smiles>

$\left(377 \mathrm{MHz}, \mathrm{CDCl}_{3}\right)$

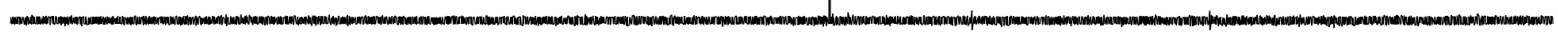

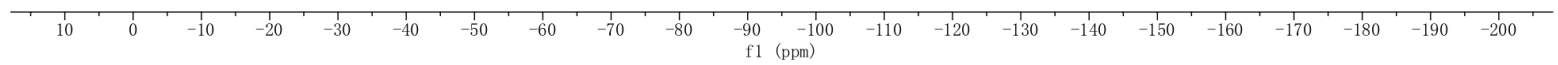



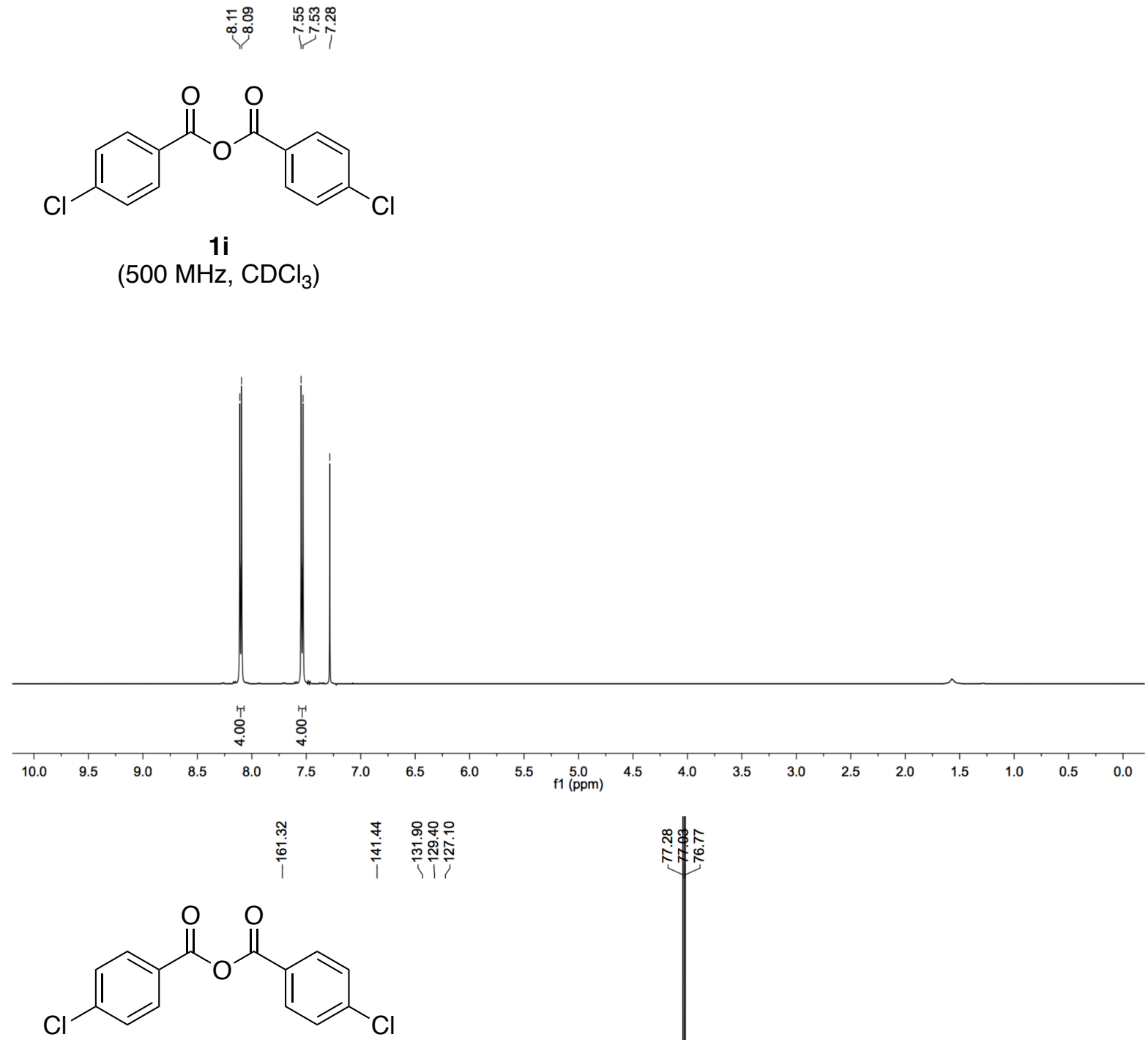

$1 \mathbf{i}$

$\left(125 \mathrm{MHz}, \mathrm{CDCl}_{3}\right)$

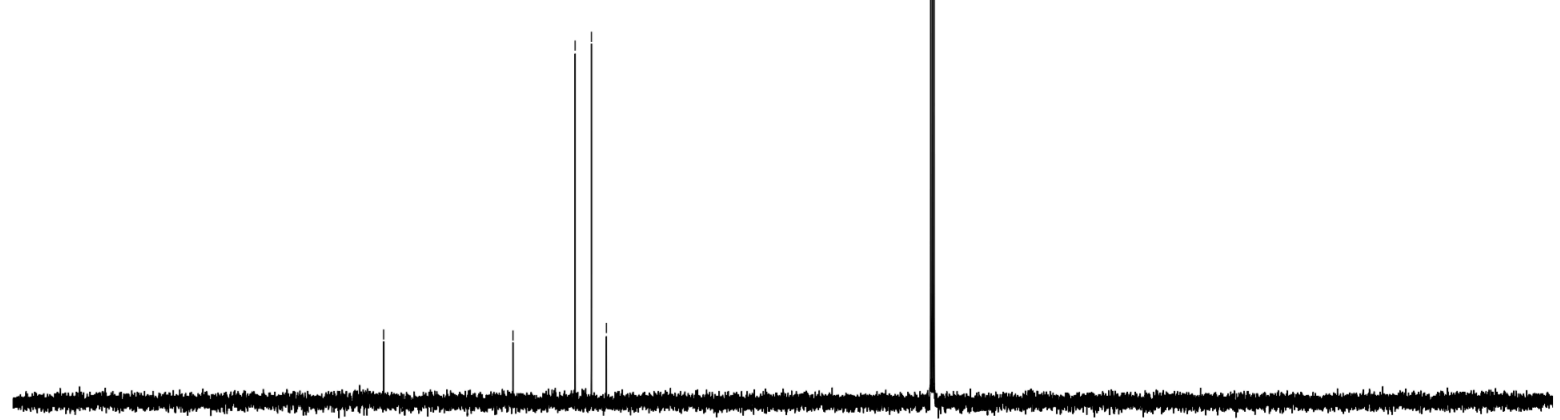

$\begin{array}{llllllllllllllllllllllll}210 & 200 & 190 & 180 & 170 & 160 & 150 & 140 & 130 & 120 & 110 & 100 & 100 & 80 & 70 & 60 & 50 & 40 & 30 & 20 & 10 & 0 & -10\end{array}$

SI-11 

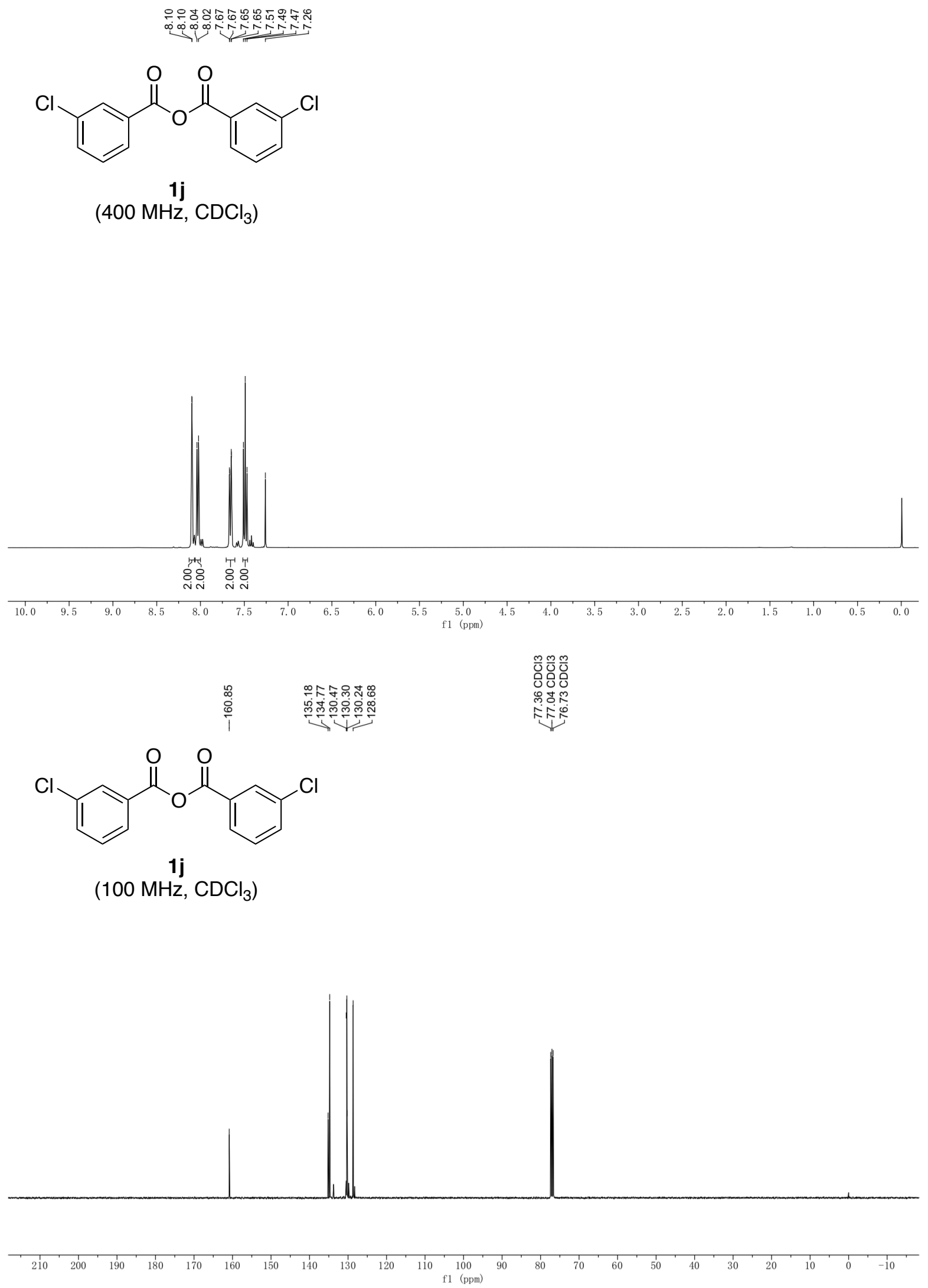

SI-12 

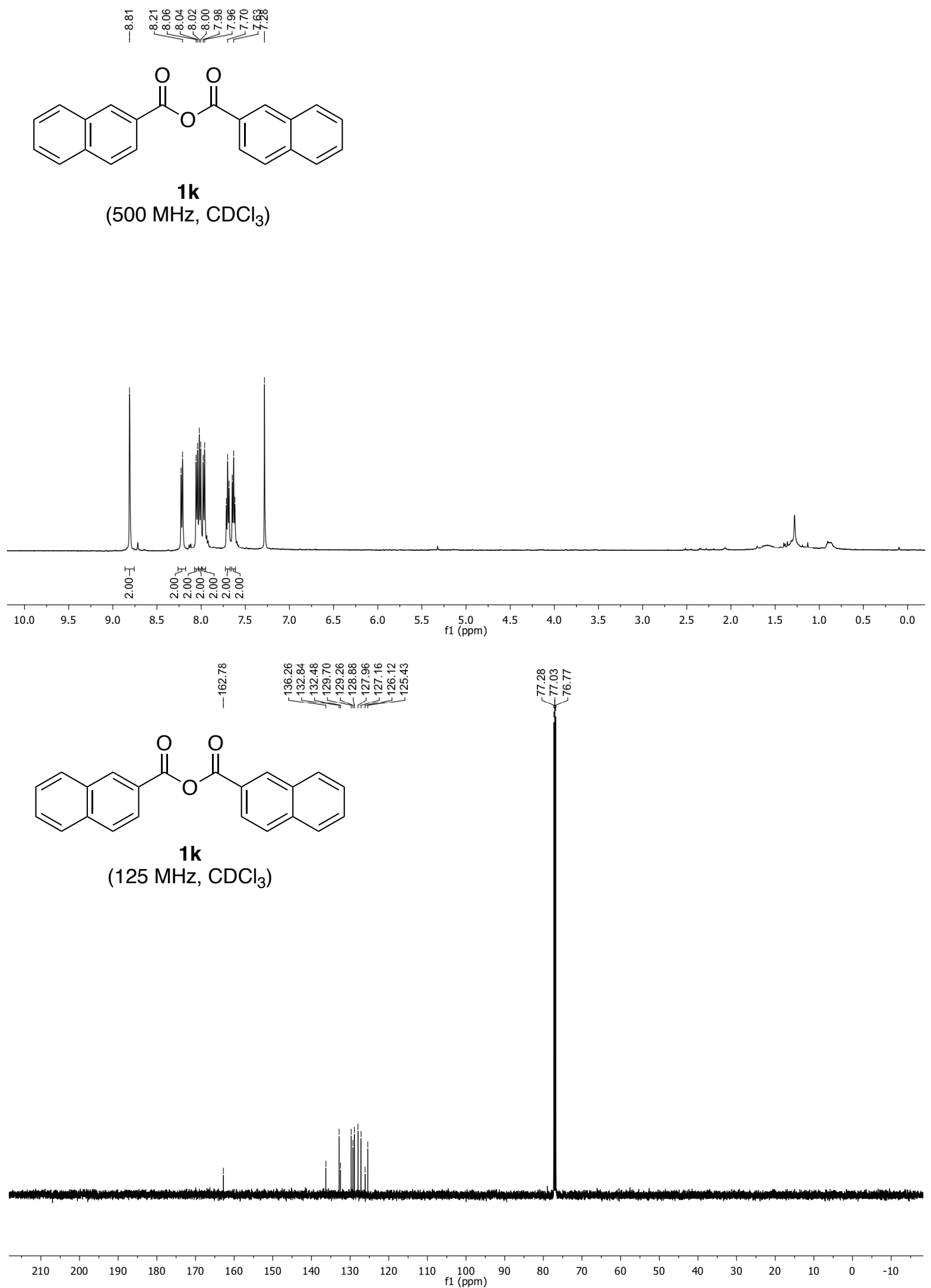

SI-13 


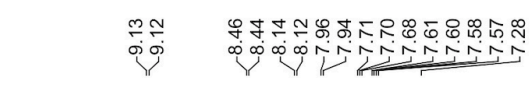<smiles>O=C(OC(=O)c1cccc2ccccc12)c1cccc2ccccc12</smiles>

11

(500 MHz, $\mathrm{CDCl}_{3}$ )
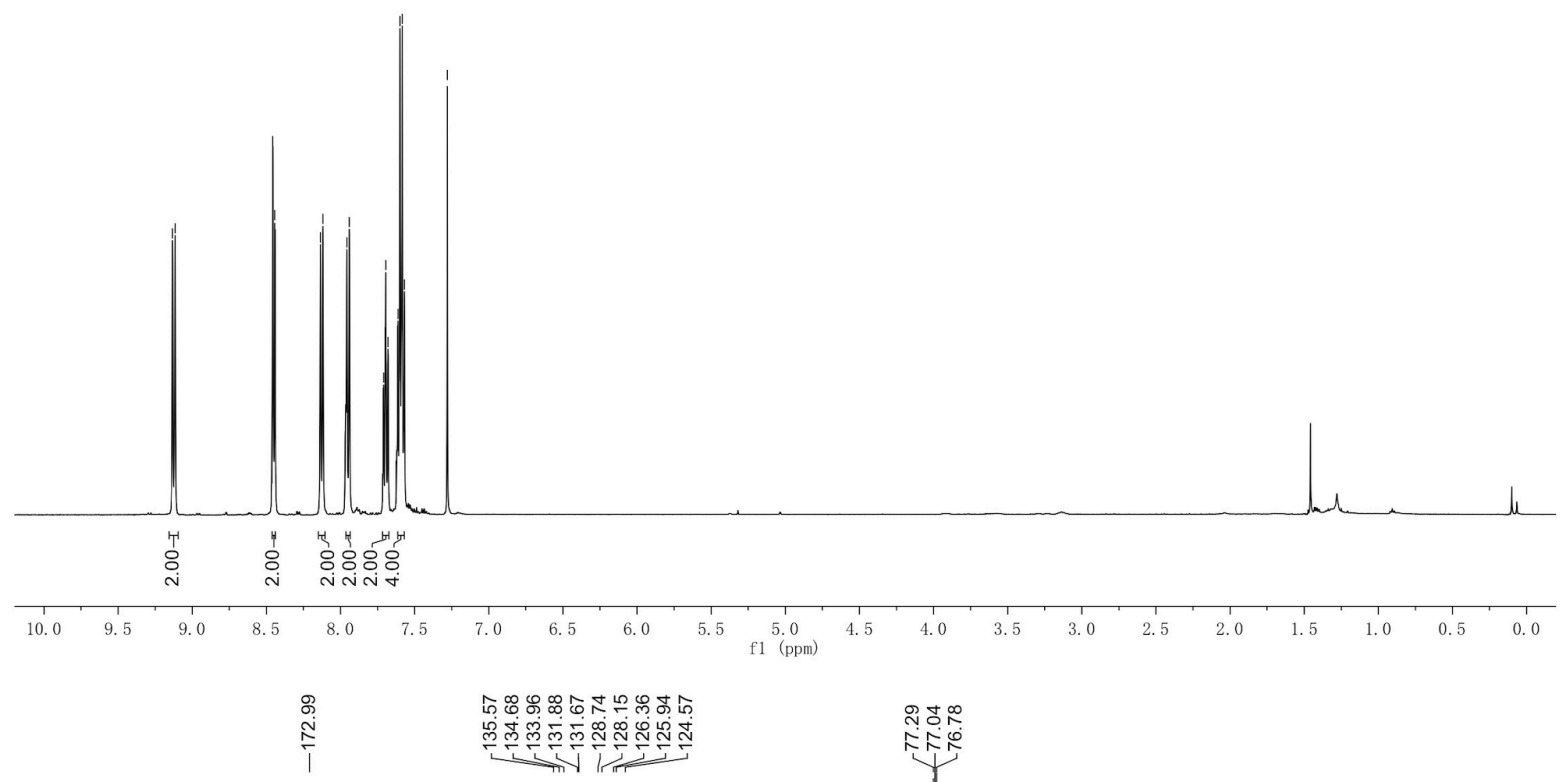<smiles>O=C(OC(=O)c1cccc2ccccc12)c1cccc2ccccc12</smiles>

11

(125 MHz, $\mathrm{CDCl}_{3}$ )

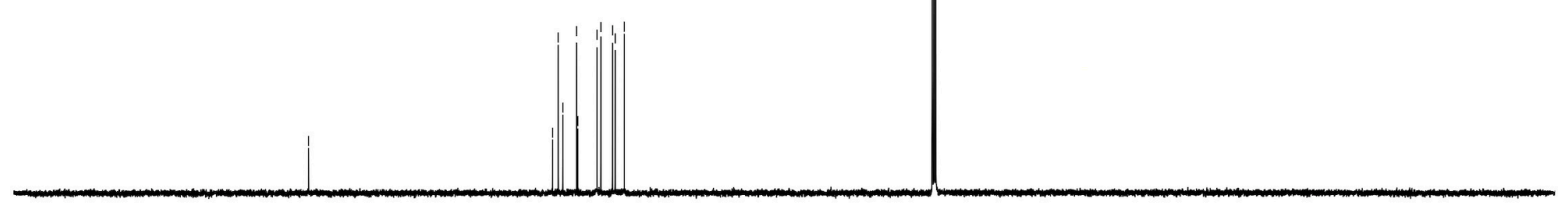

SI-14 


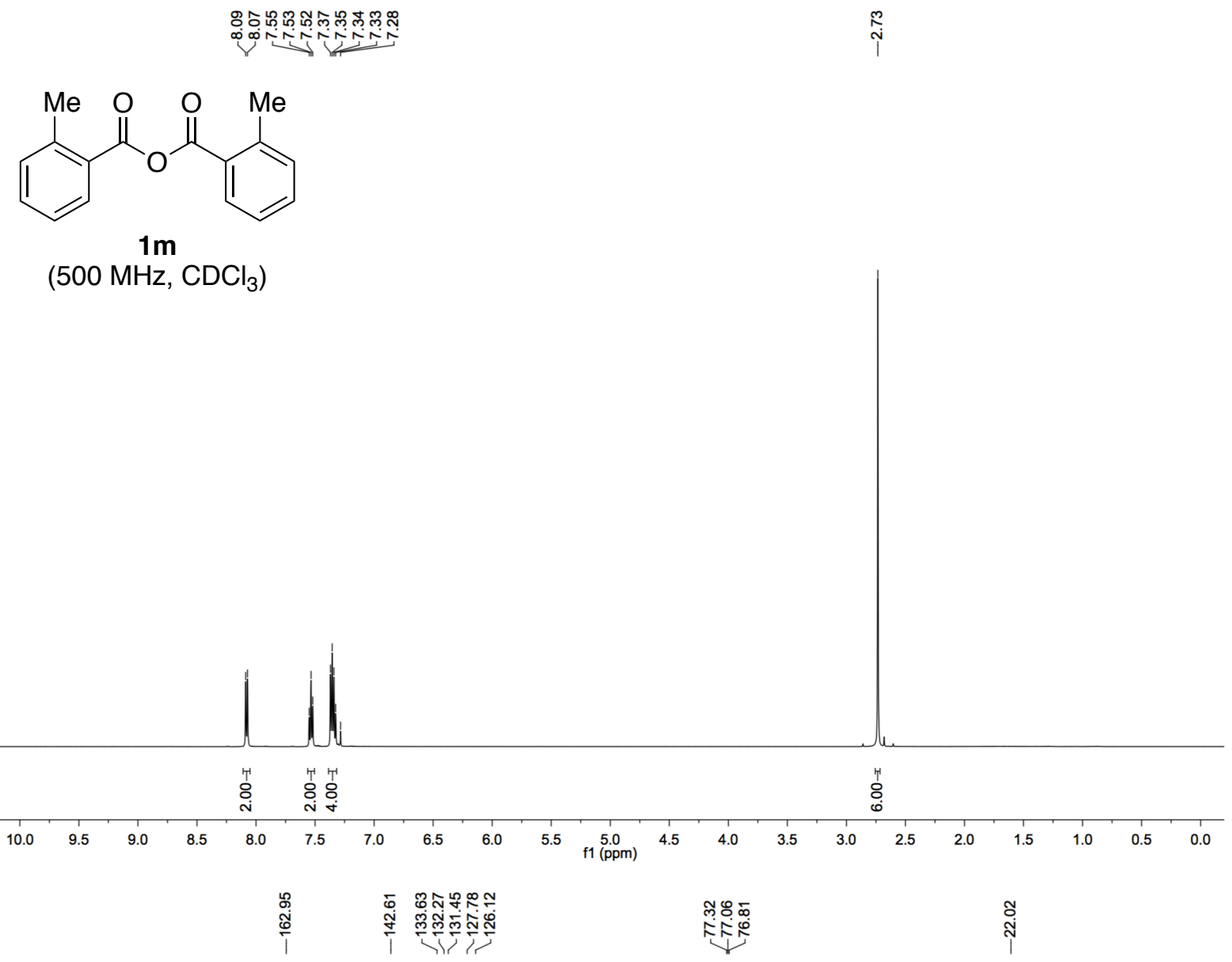<smiles>Cc1ccccc1C(=O)OC(=O)c1ccccc1C</smiles>

$1 \mathrm{~m}$

$\left(125 \mathrm{MHz}, \mathrm{CDCl}_{3}\right)$

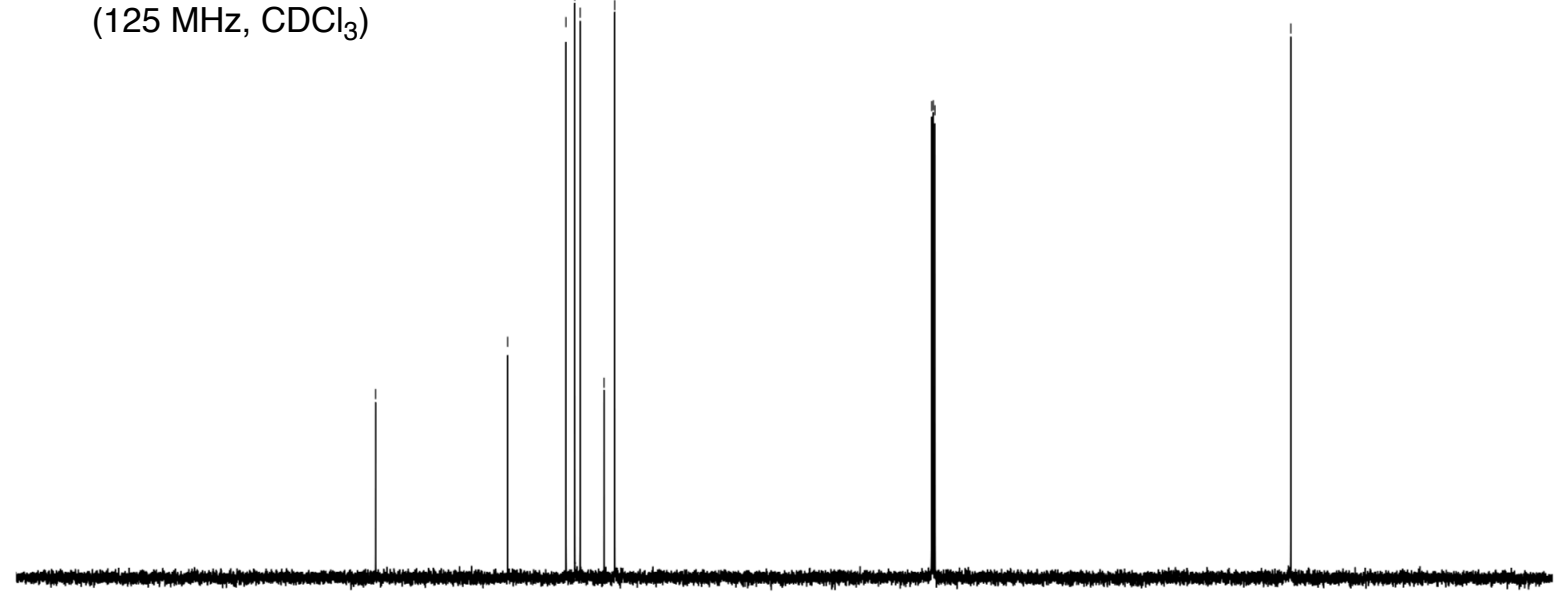

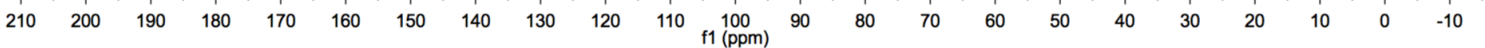

SI-15 


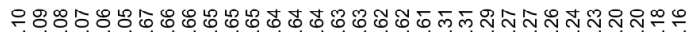

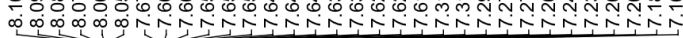<smiles>O=C(OC(=O)c1ccccc1F)c1ccccc1F</smiles>

1n $\left(400 \mathrm{MHz}, \mathrm{CDCl}_{3}\right)$
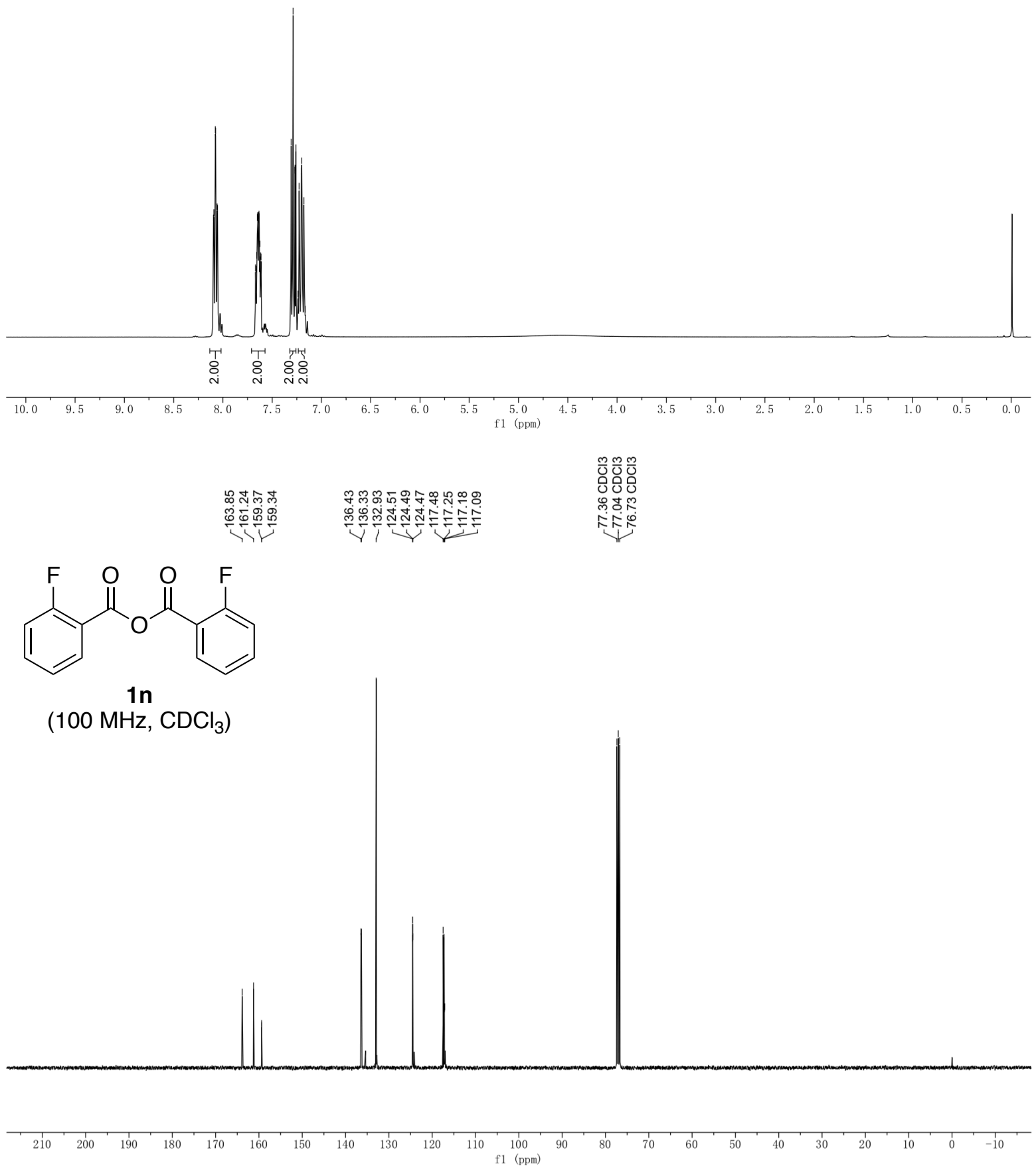

SI-16 


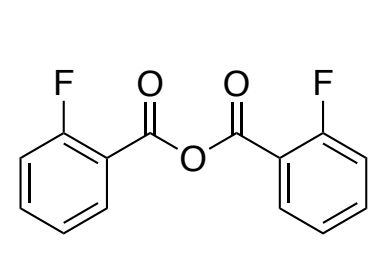

1n

$\left(377 \mathrm{MHz}, \mathrm{CDCl}_{3}\right)$

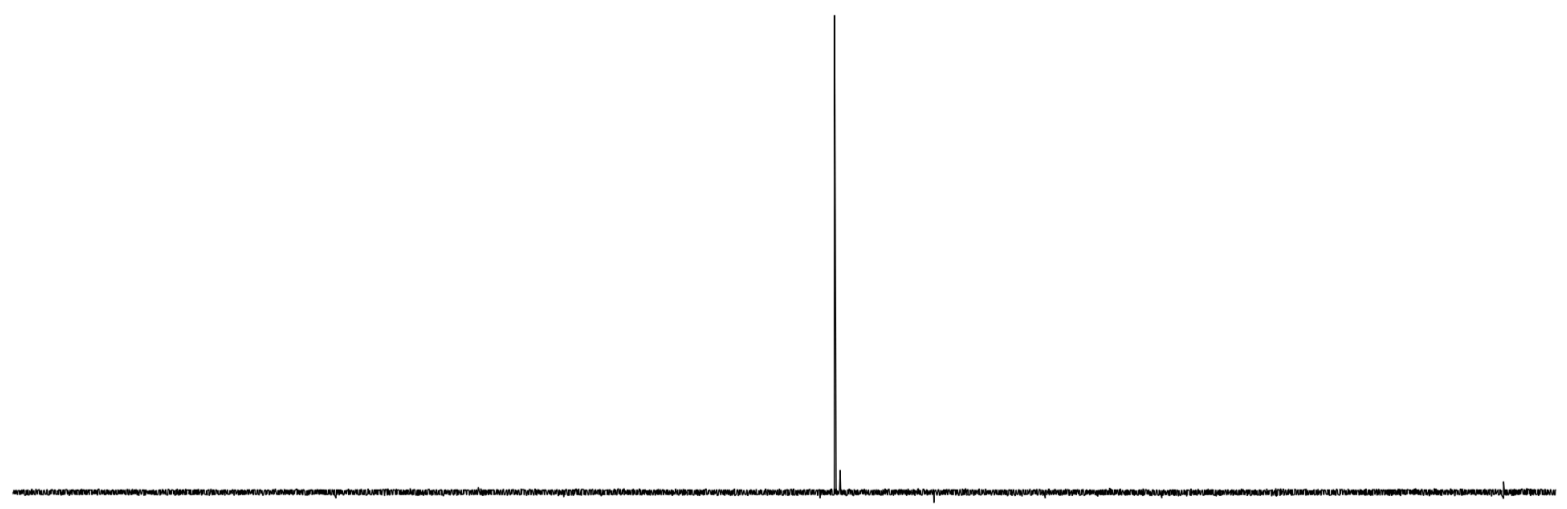

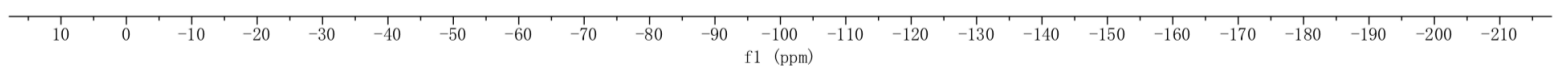




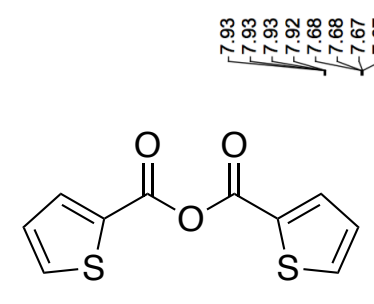

10

(500 MHz, $\mathrm{CDCl}_{3}$ )
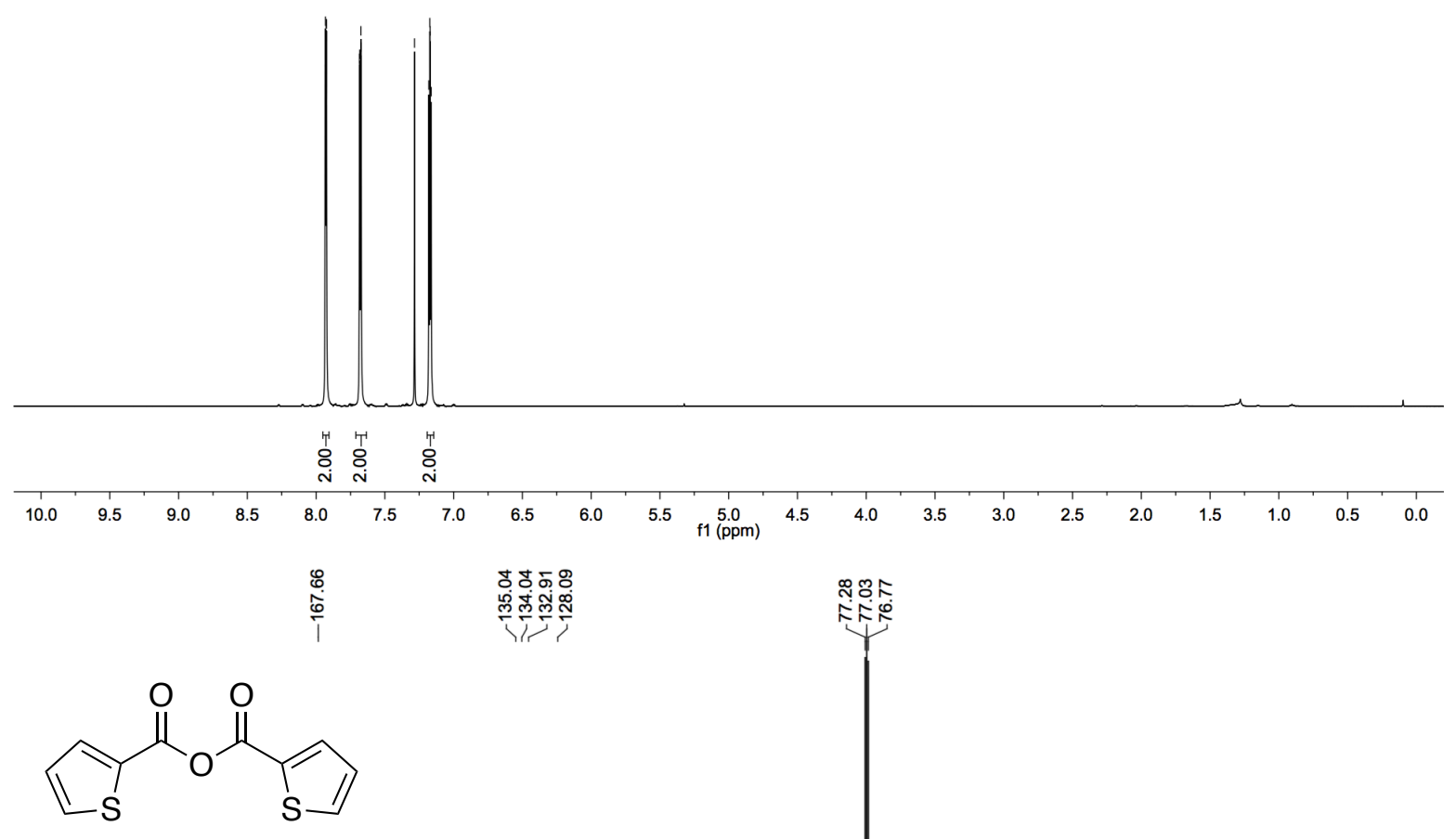

10

(125 MHz, $\mathrm{CDCl}_{3}$ )

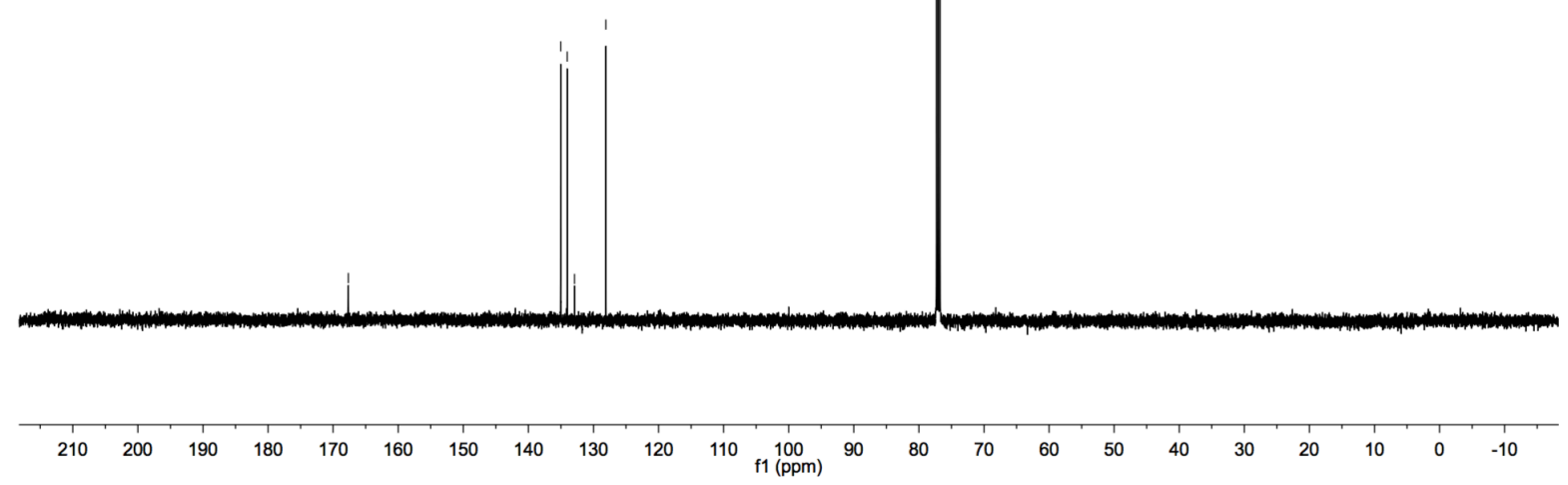

SI-18 

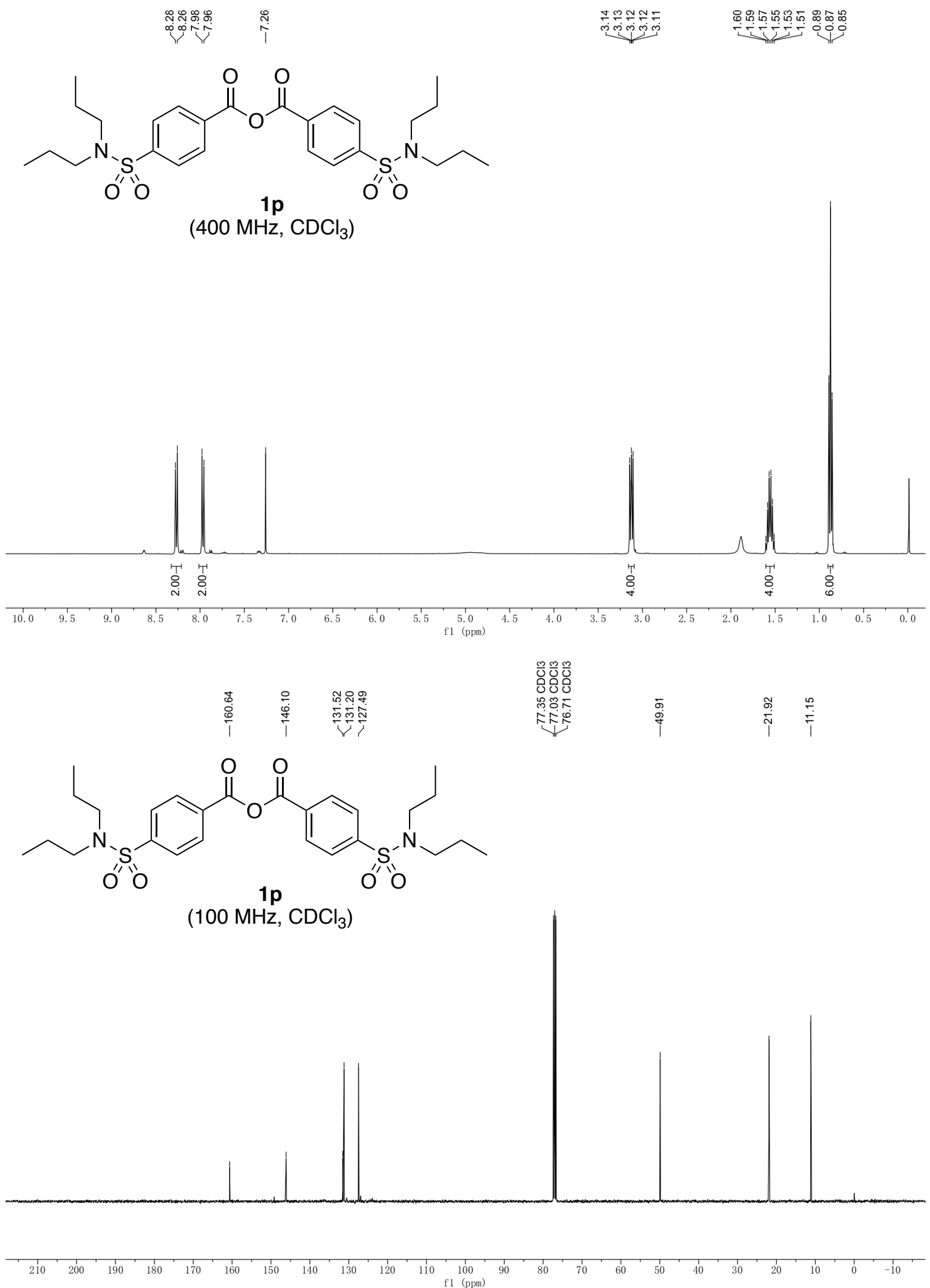

SI-19 

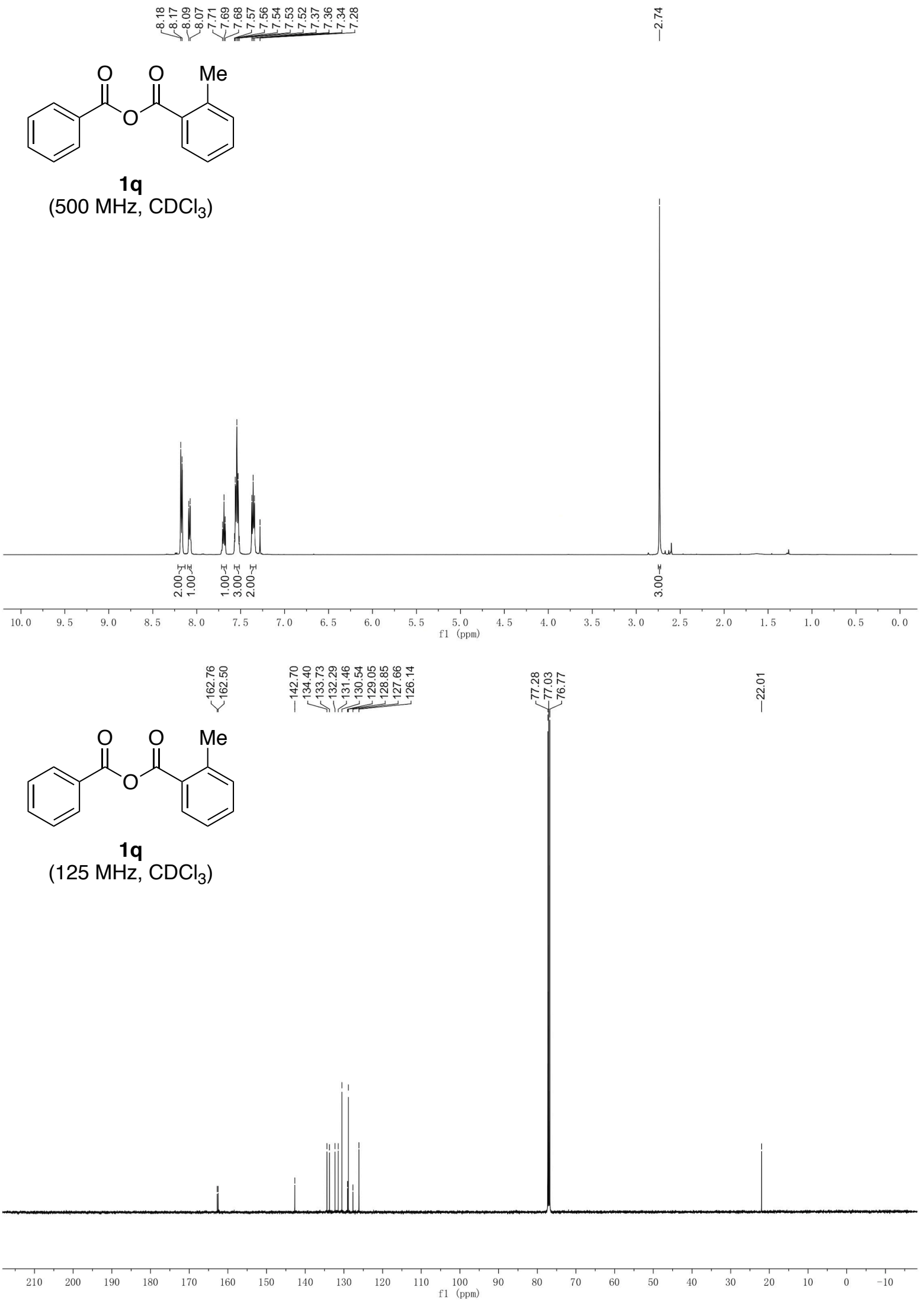

SI-20 

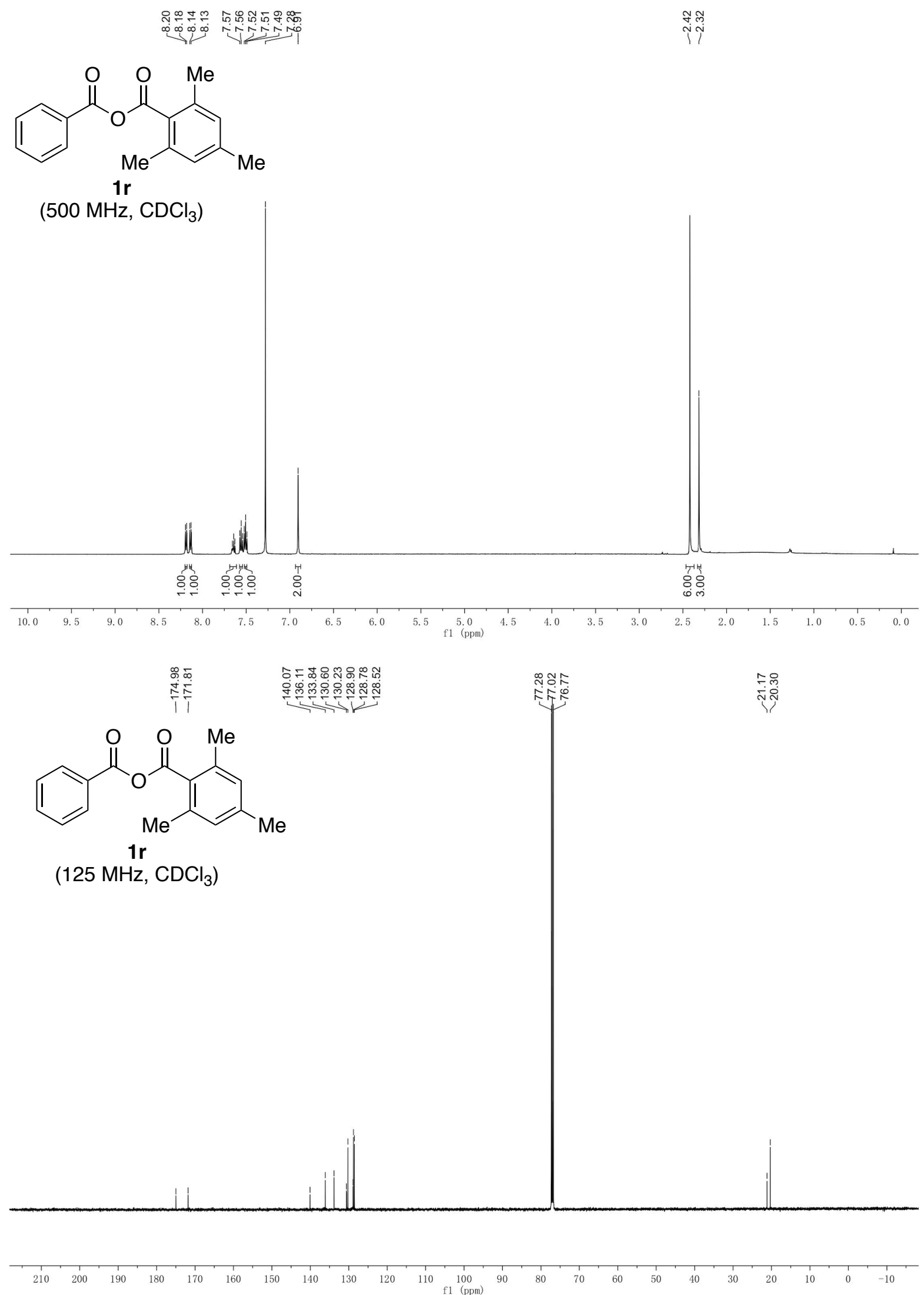

SI-21 


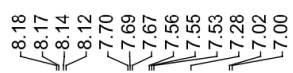<smiles>COc1ccc(C(=O)OC(=O)c2ccccc2)cc1</smiles>

$1 \mathrm{~s}$

$\left(500 \mathrm{MHz}, \mathrm{CDCl}_{3}\right)$
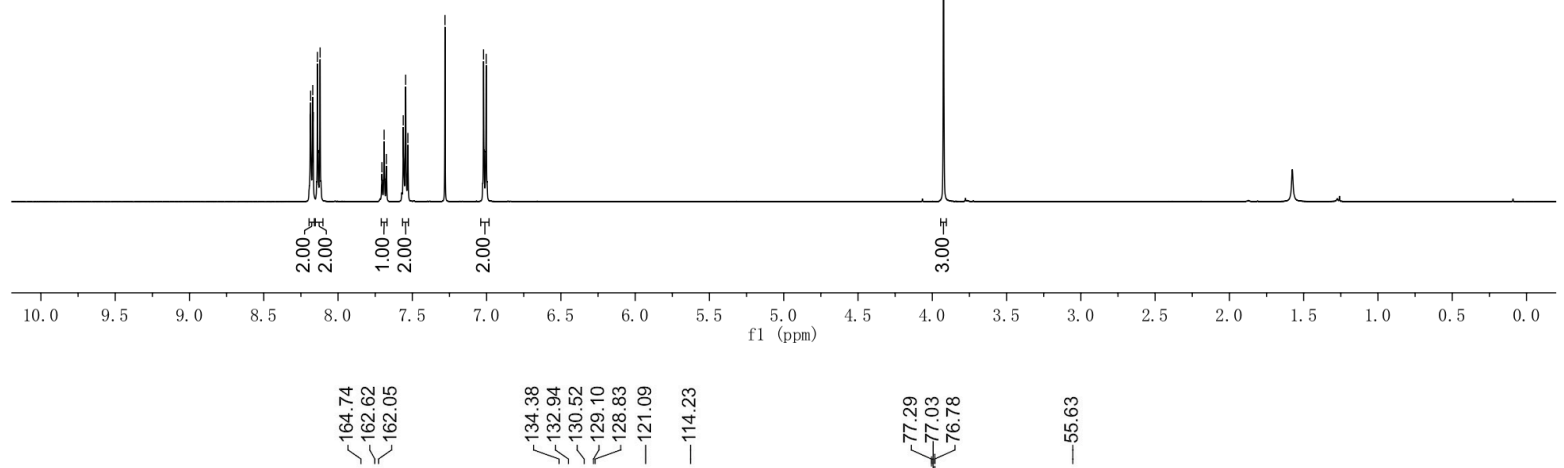<smiles>COc1ccc(C(=O)OC(=O)c2ccccc2)cc1</smiles>

1s

$\left(125 \mathrm{MHz}, \mathrm{CDCl}_{3}\right)$
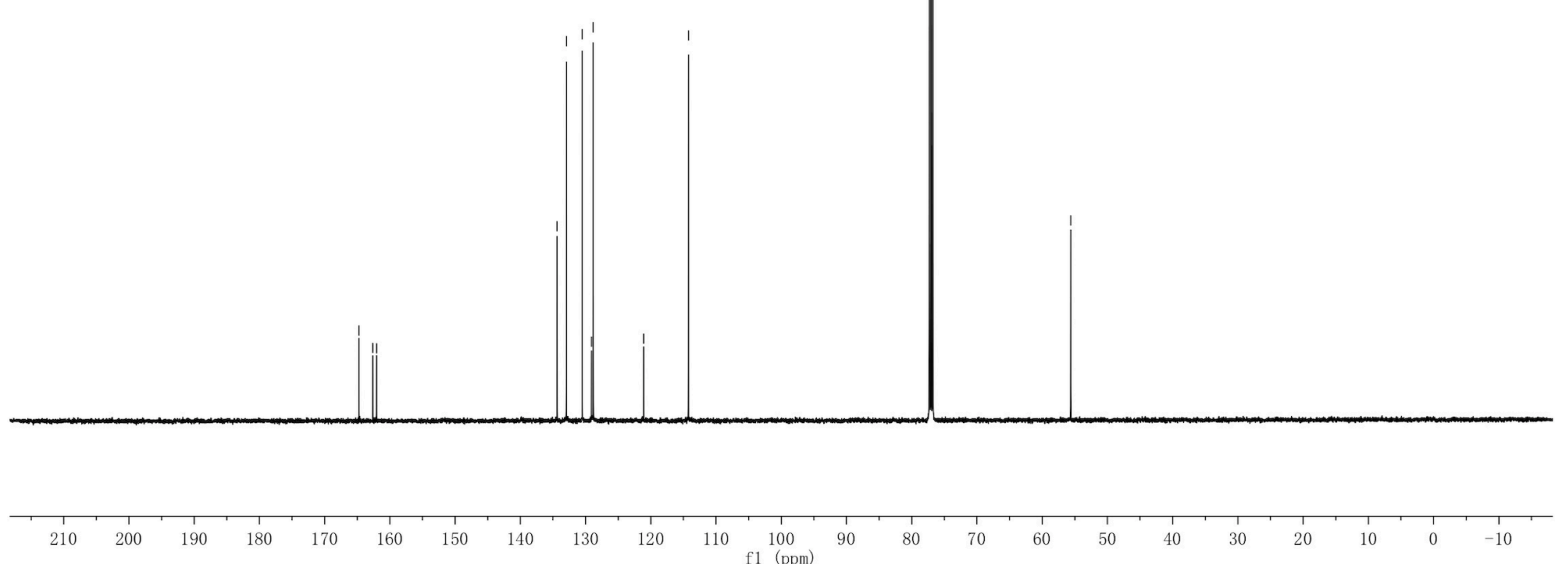

SI-22 

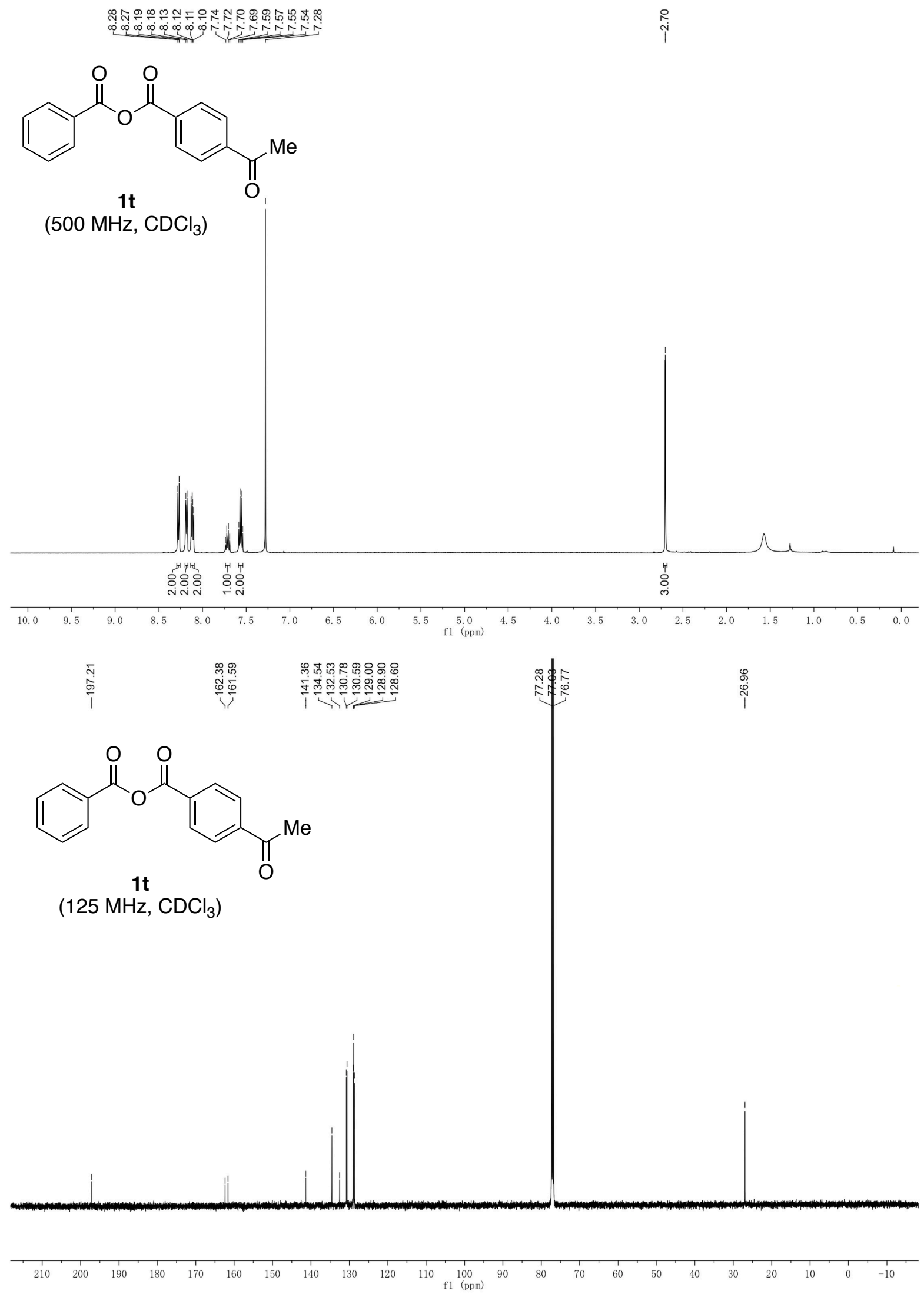

SI-23 


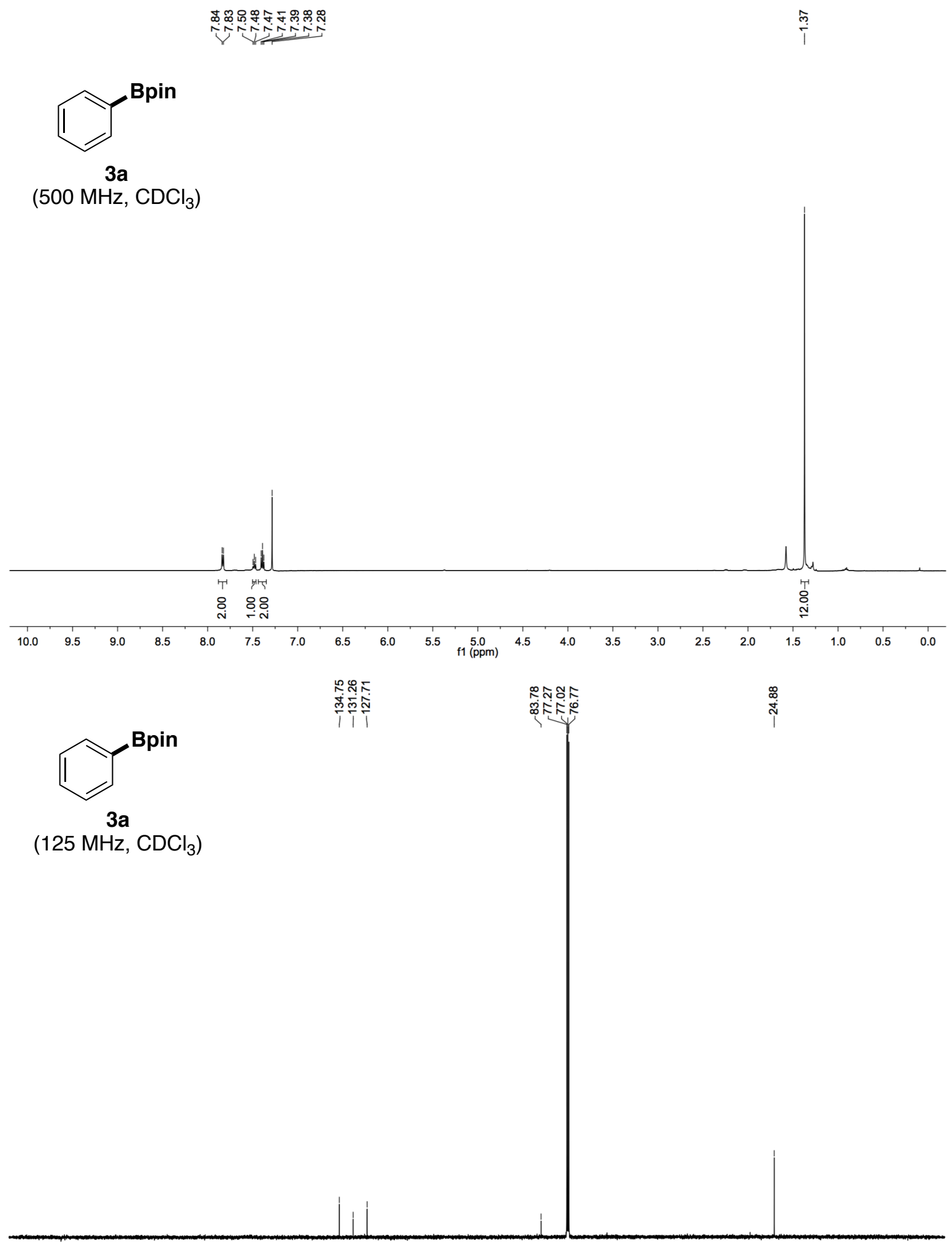




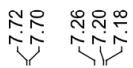

गु<smiles>Cc1ccc(Br)cc1</smiles>

3b

$\left(400 \mathrm{MHz}, \mathrm{CDCl}_{3}\right)$
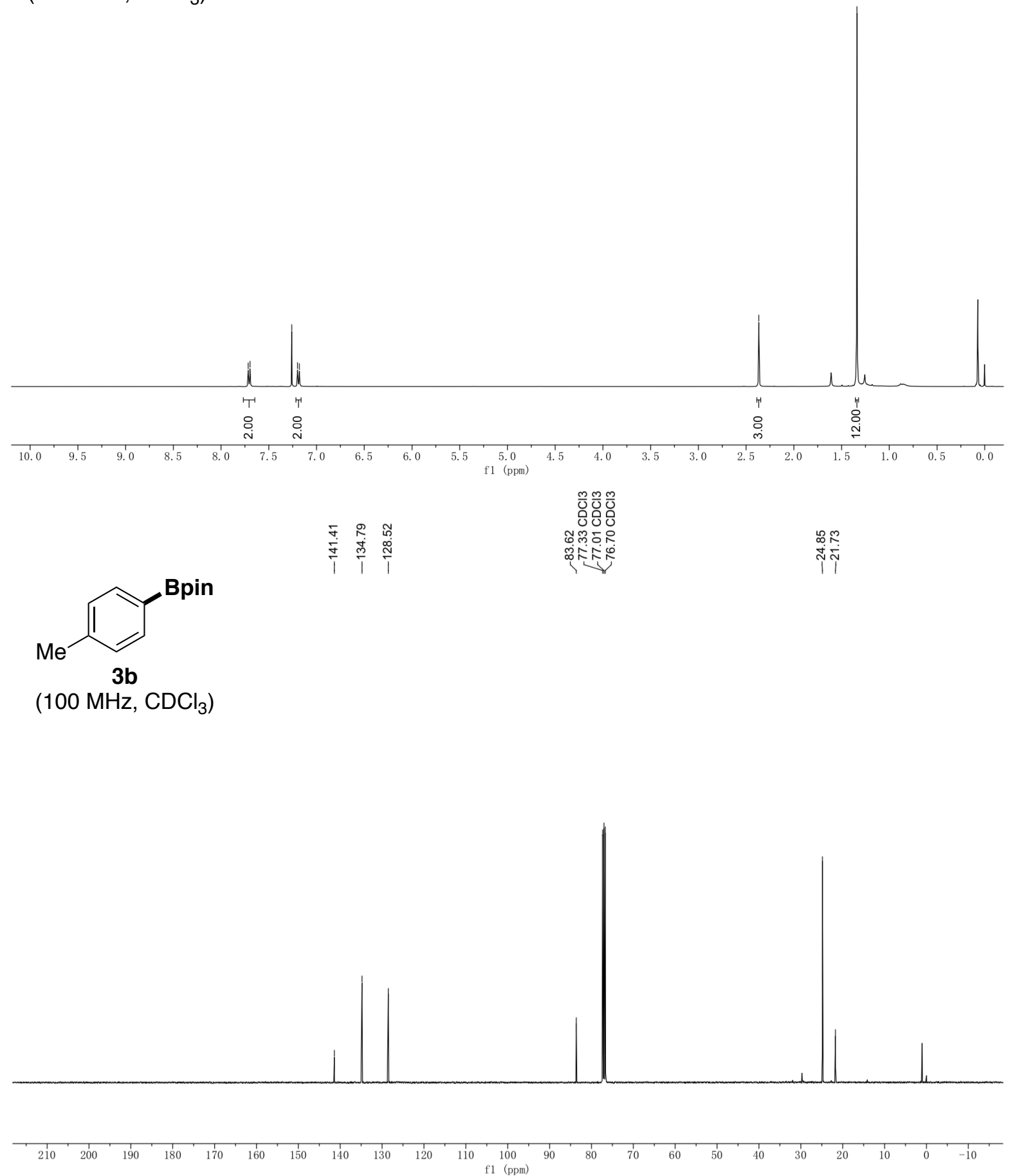

SI-25 

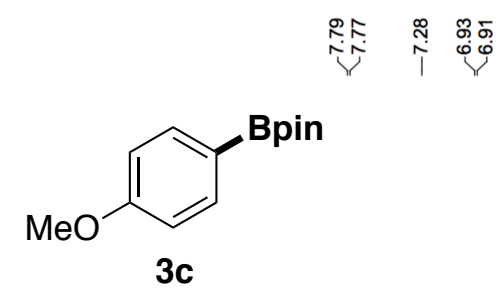

$\stackrel{\infty}{\infty}$

$\stackrel{\infty}{\stackrel{\infty}{\Gamma}}$

$\left(500 \mathrm{MHz}, \mathrm{CDCl}_{3}\right)$
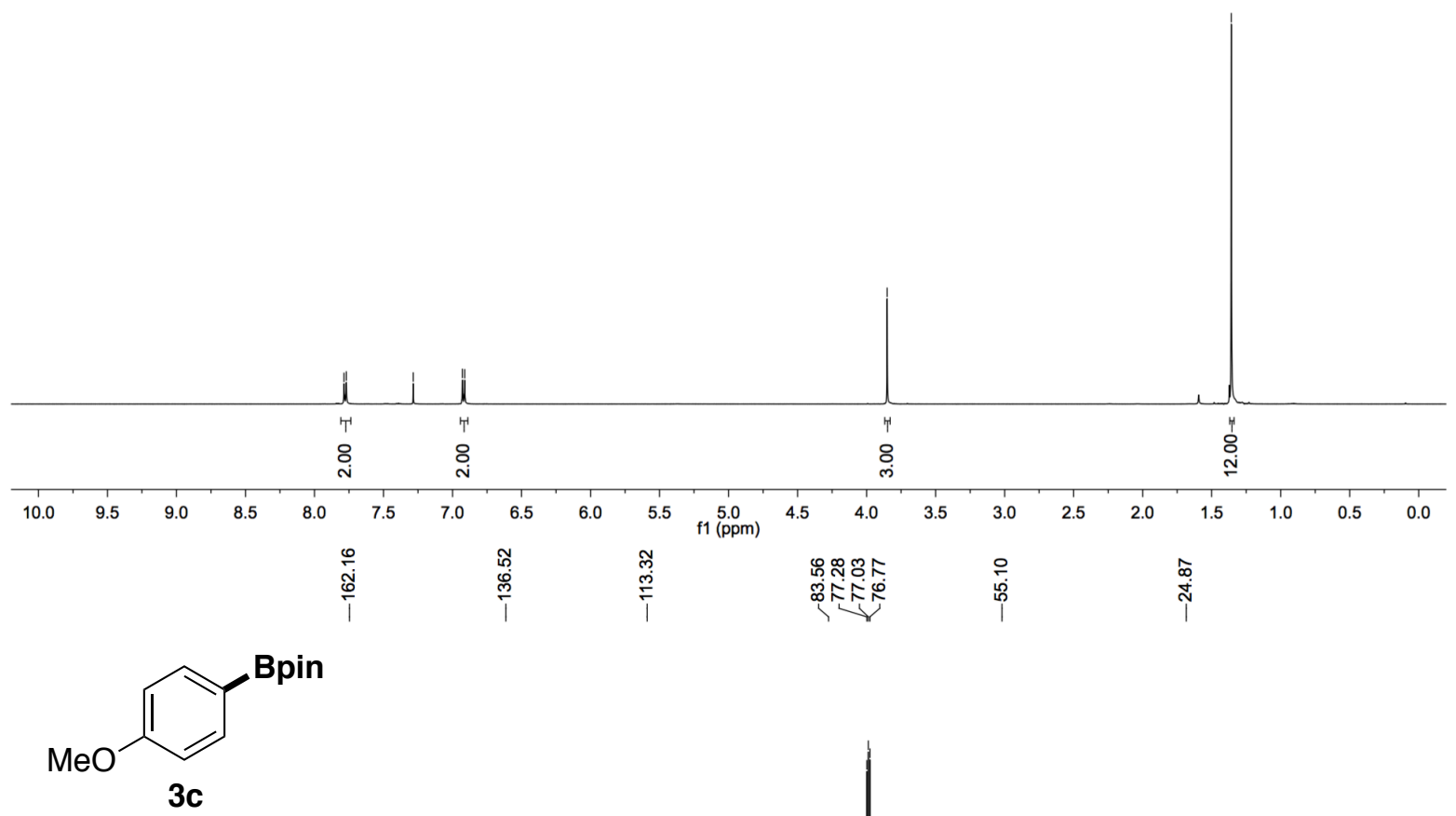

$\left(125 \mathrm{MHz}, \mathrm{CDCl}_{3}\right)$

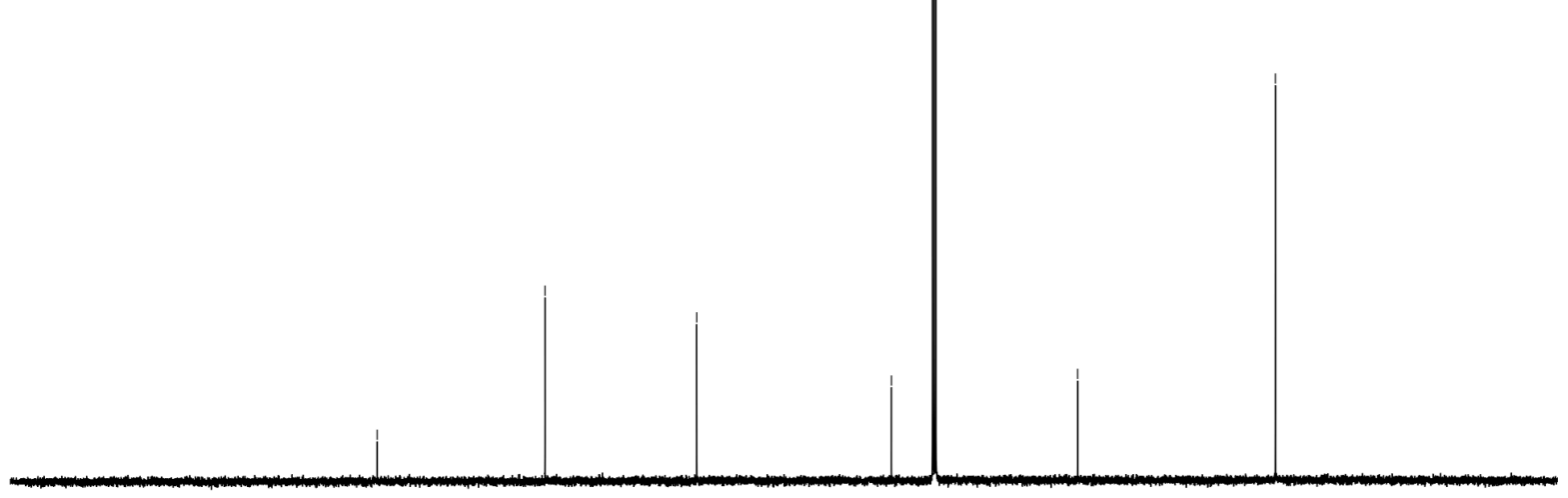

$\begin{array}{lllllllllllllllllllllllllllllll}210 & 200 & 190 & 180 & 170 & 160 & 150 & 140 & 130 & 120 & 110 & 100 & 90 & 80 & 70 & 60 & 50 & 40 & 30 & 20 & 10 & 0 & -10\end{array}$ 


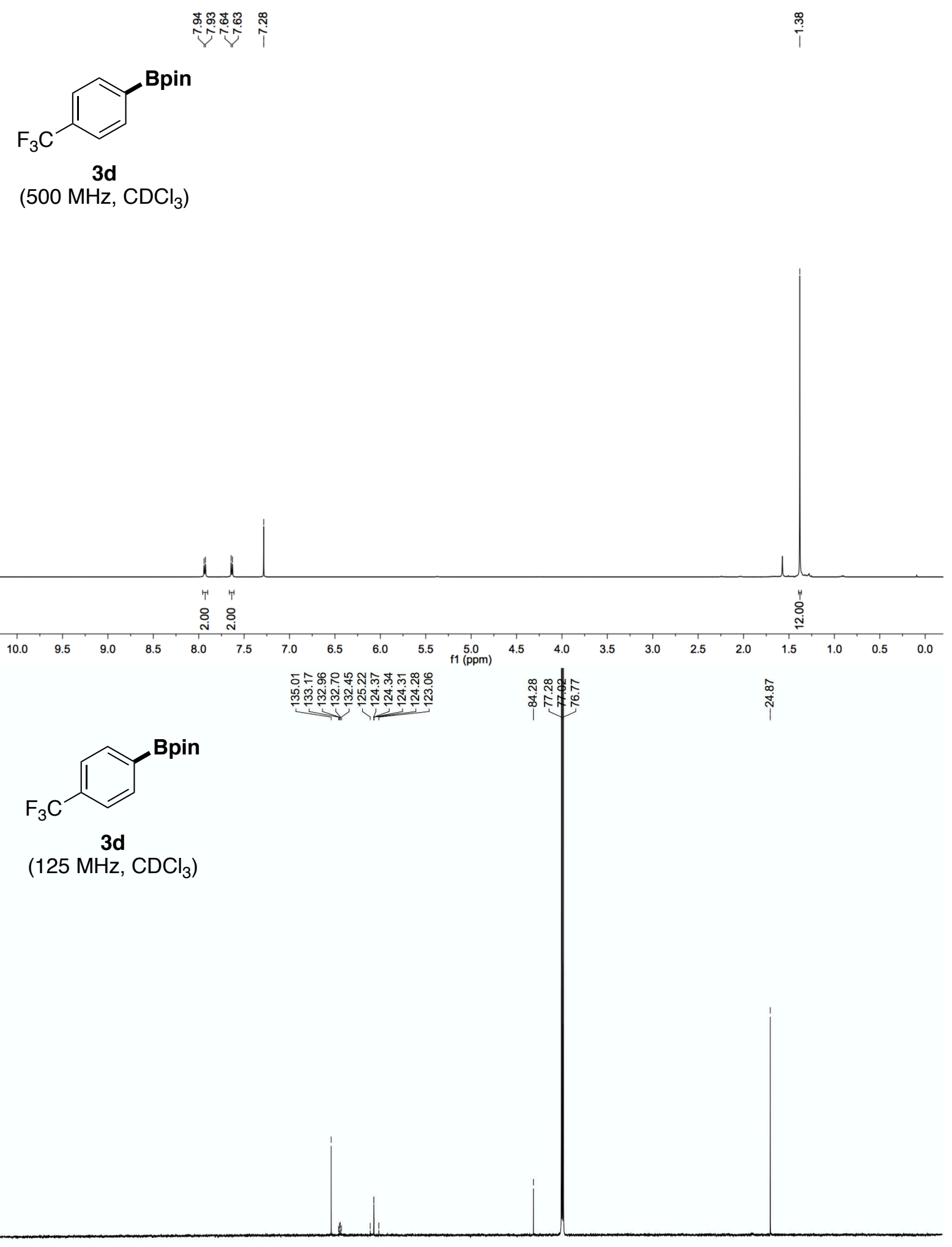

$\begin{array}{lllllllllllllllllllllll}210 & 200 & 190 & 180 & 170 & 160 & 150 & 140 & 130 & 120 & 110 & \begin{array}{c}100 \\ \mathrm{f} 1(\mathrm{ppm})\end{array} & 90 & 80 & 70 & 60 & 50 & 40 & 30 & 20 & 10 & 0 & -10\end{array}$ 


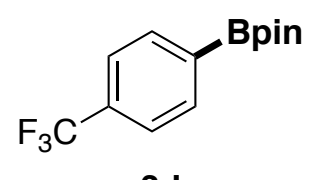

3d

(471 MHz, $\mathrm{CDCl}_{3}$ )

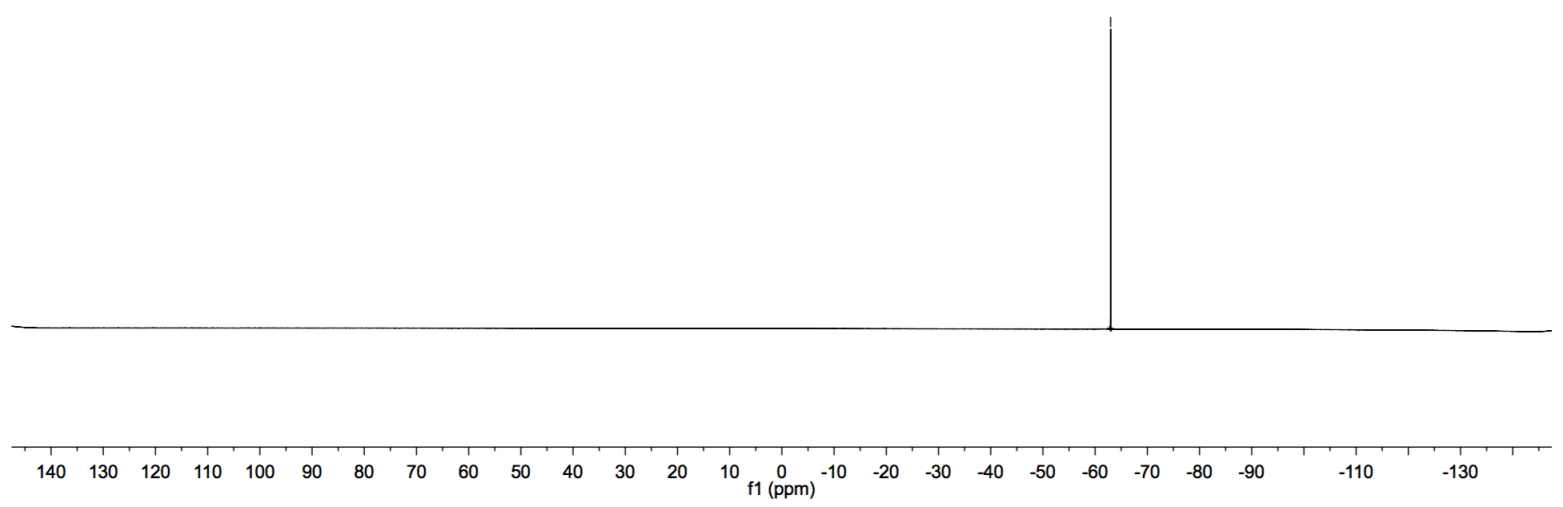



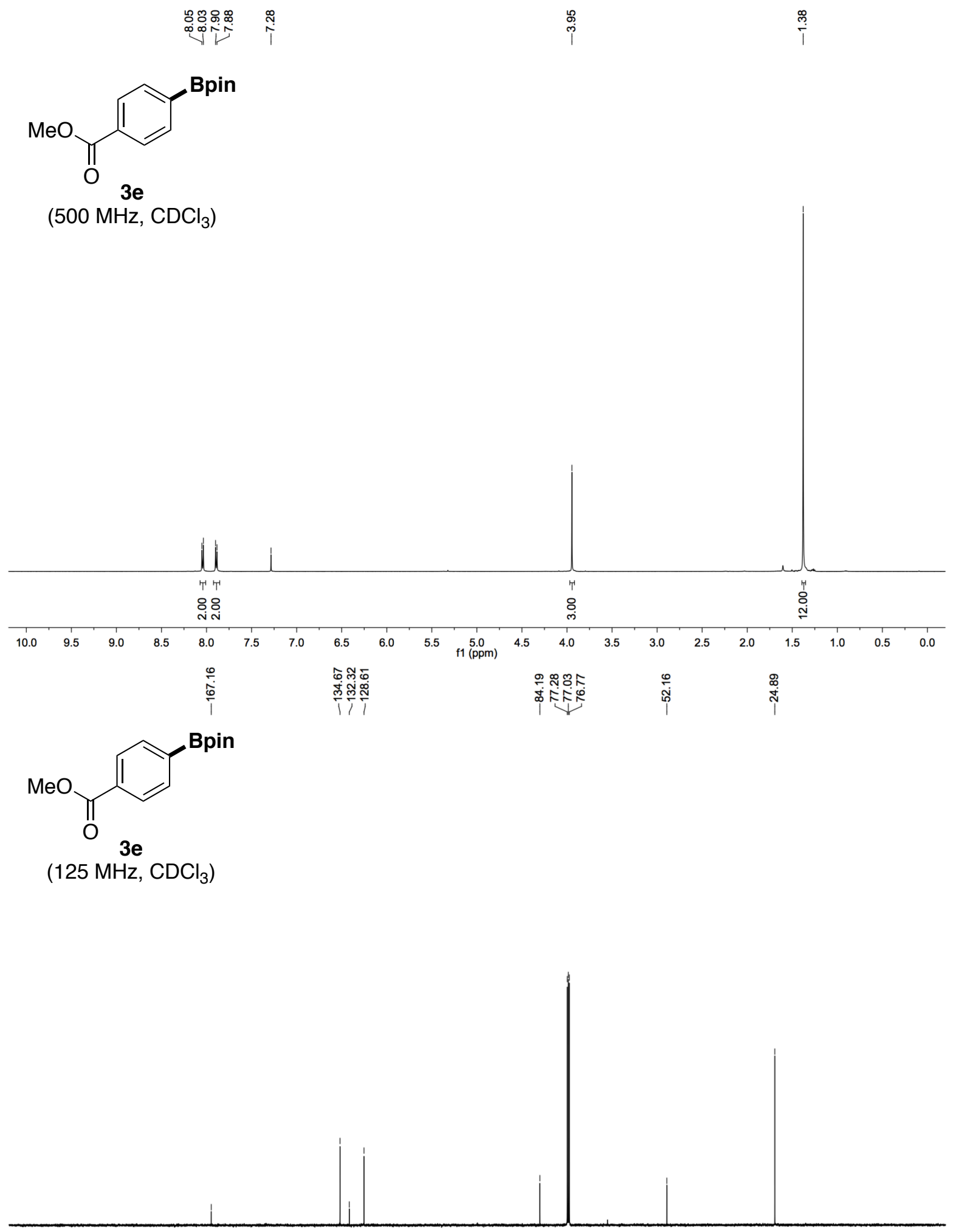

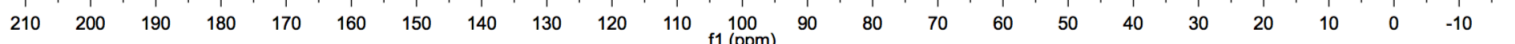




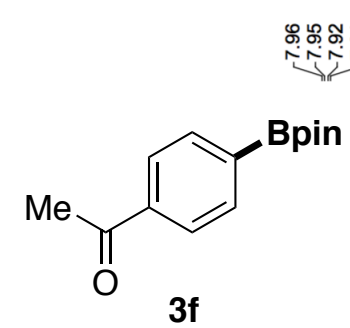

$\left(500 \mathrm{MHz}, \mathrm{CDCl}_{3}\right)$
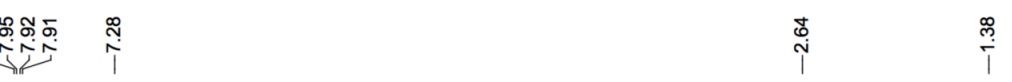

\section{.}



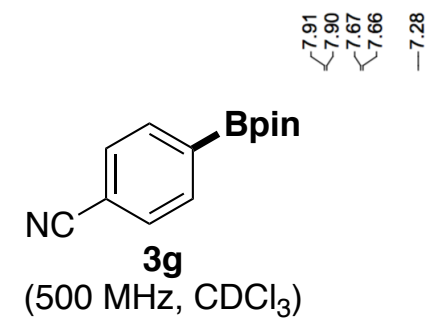

$\left(500 \mathrm{MHz} \mathrm{CDCl}_{3}\right)$

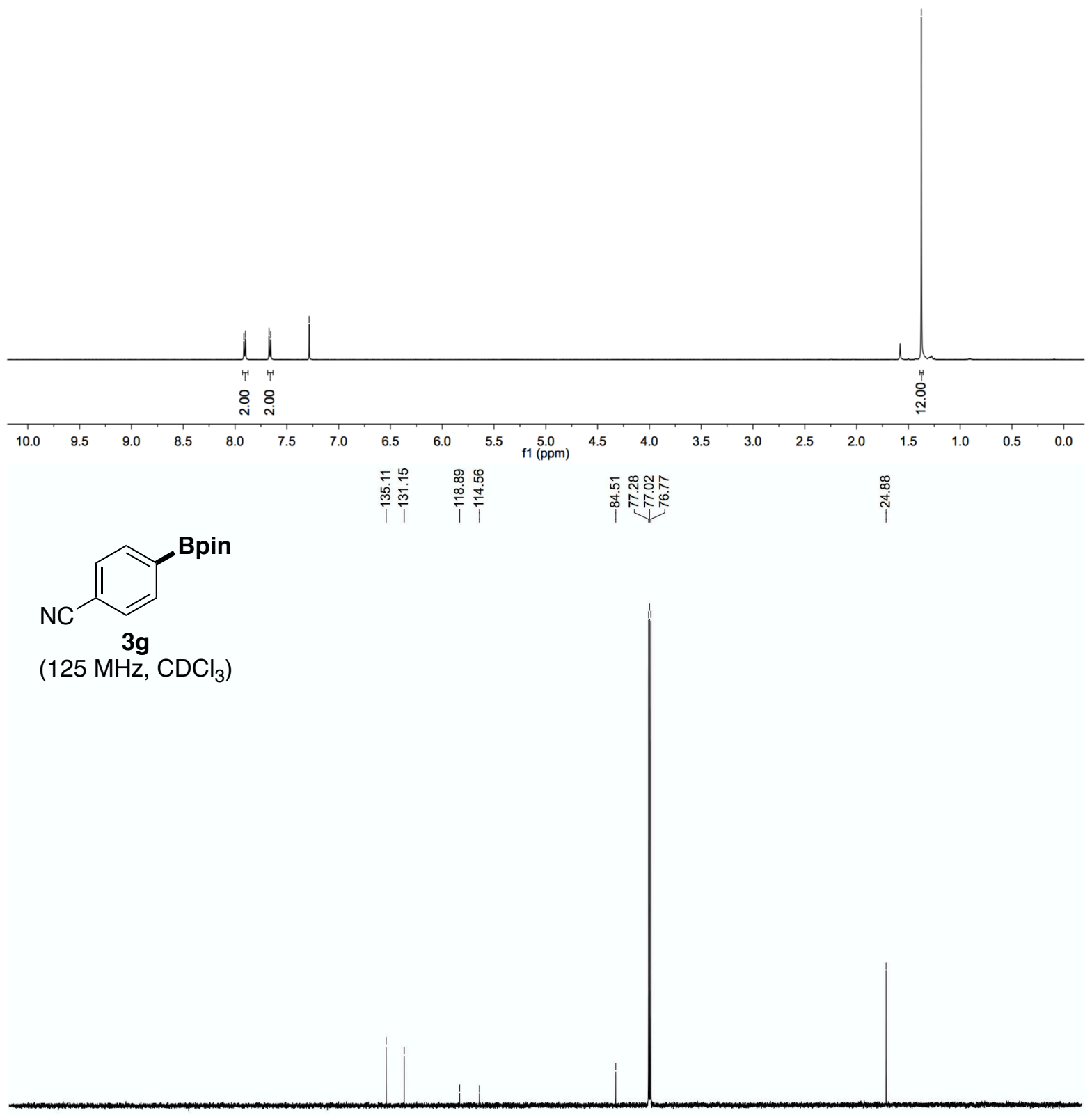

$\begin{array}{lllllllllllllllllllllllll}210 & 200 & 190 & 180 & 170 & 160 & 150 & 140 & 130 & 120 & 110 & \begin{array}{l}100 \\ \mathrm{f} 1\end{array}(\mathrm{ppm}) & 90 & 80 & 70 & 60 & 50 & 40 & 30 & 20 & 10 & 0 & -10\end{array}$ 


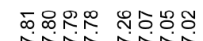

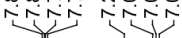

$3 \mathrm{~h}$

$\left(400 \mathrm{MHz}, \mathrm{CDCl}_{3}\right)$<smiles>Fc1ccc(Br)cc1</smiles>

$\stackrel{i}{\stackrel{i}{m}}$

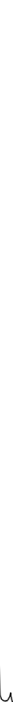

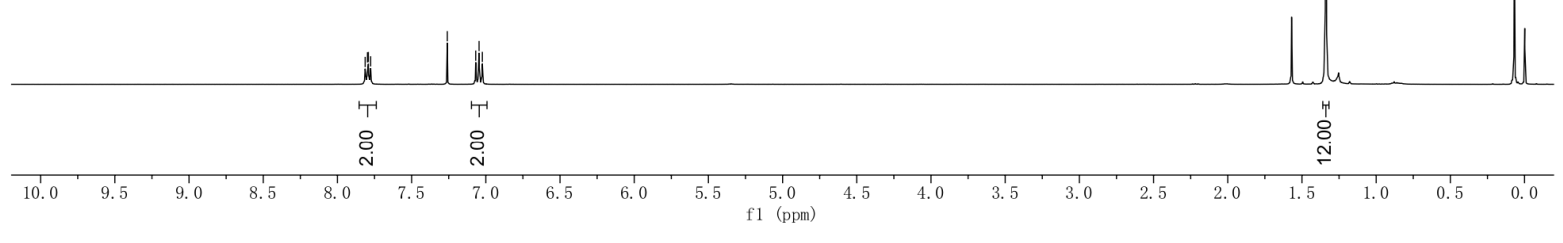

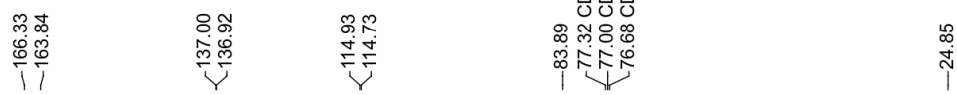

$3 \mathrm{~h}$

$\left(100 \mathrm{MHz}, \mathrm{CDCl}_{3}\right)$

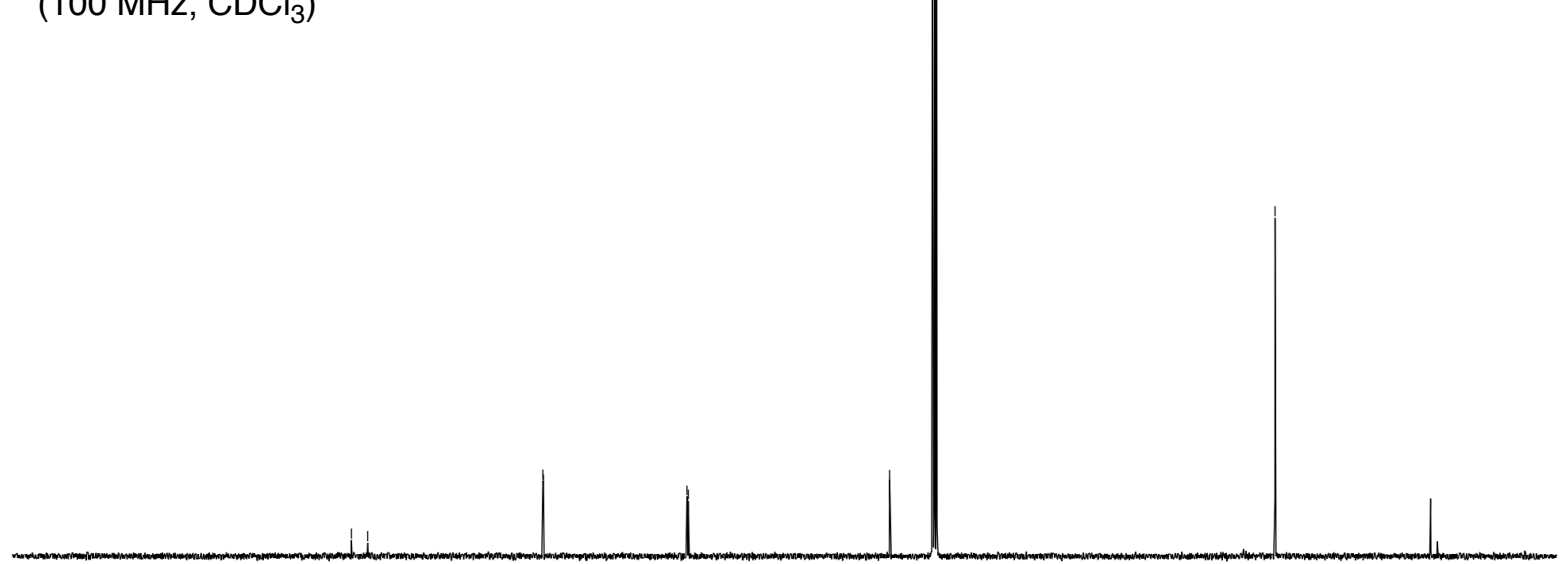

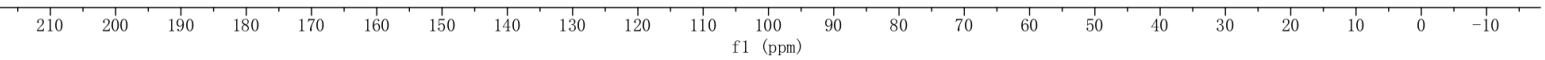

SI-32 


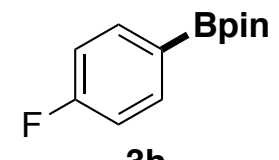

3h

(377 $\mathrm{MHz} \mathrm{CDCl}_{3}$ )
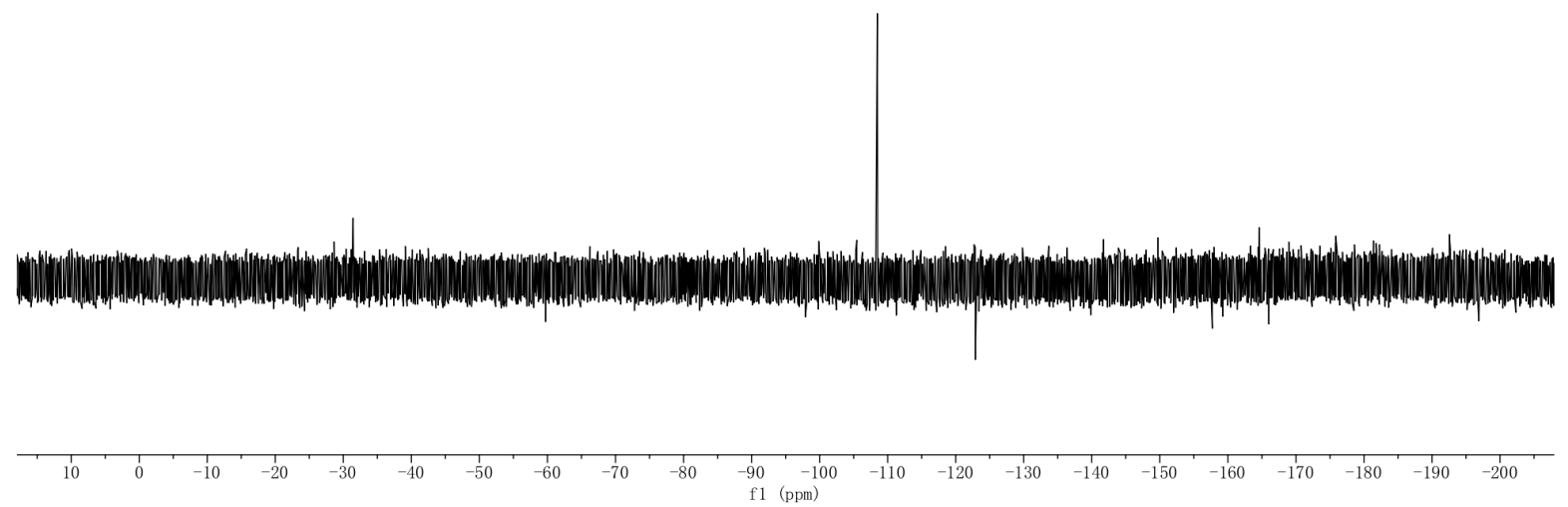


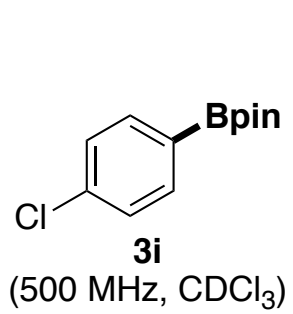

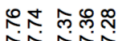

ivivi

$\left(500 \mathrm{MHz} \mathrm{CDCl}_{3}\right)$

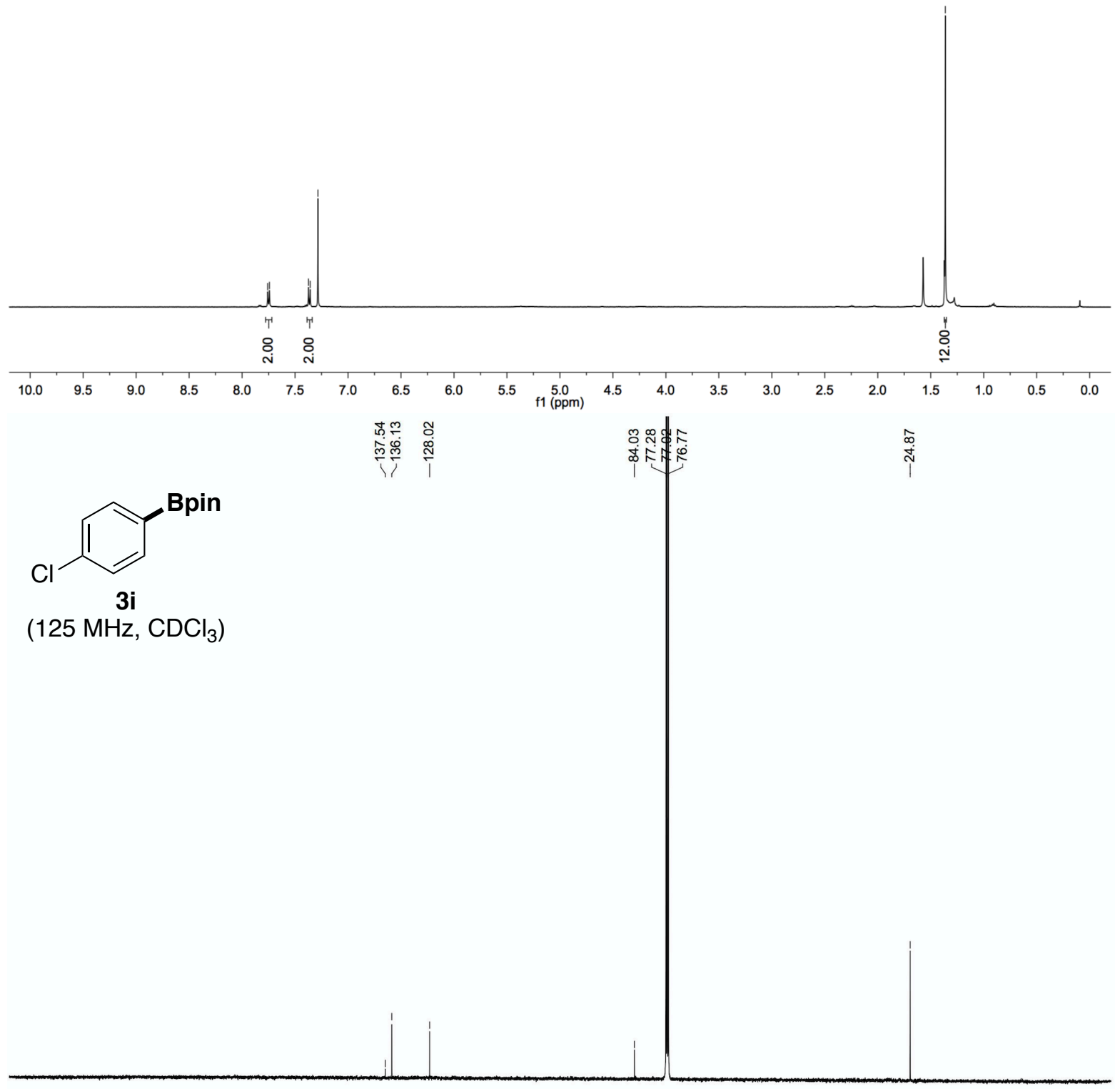

$\begin{array}{lllllllllllllllllllllll}210 & 200 & 190 & 180 & 170 & 160 & 150 & 140 & 130 & 120 & 110 & \begin{array}{c}100 \\ \mathrm{f} 1(\mathrm{ppm})\end{array} & 90 & 80 & 70 & 60 & 50 & 40 & 30 & 20 & 10 & 0 & -10\end{array}$

SI-34 

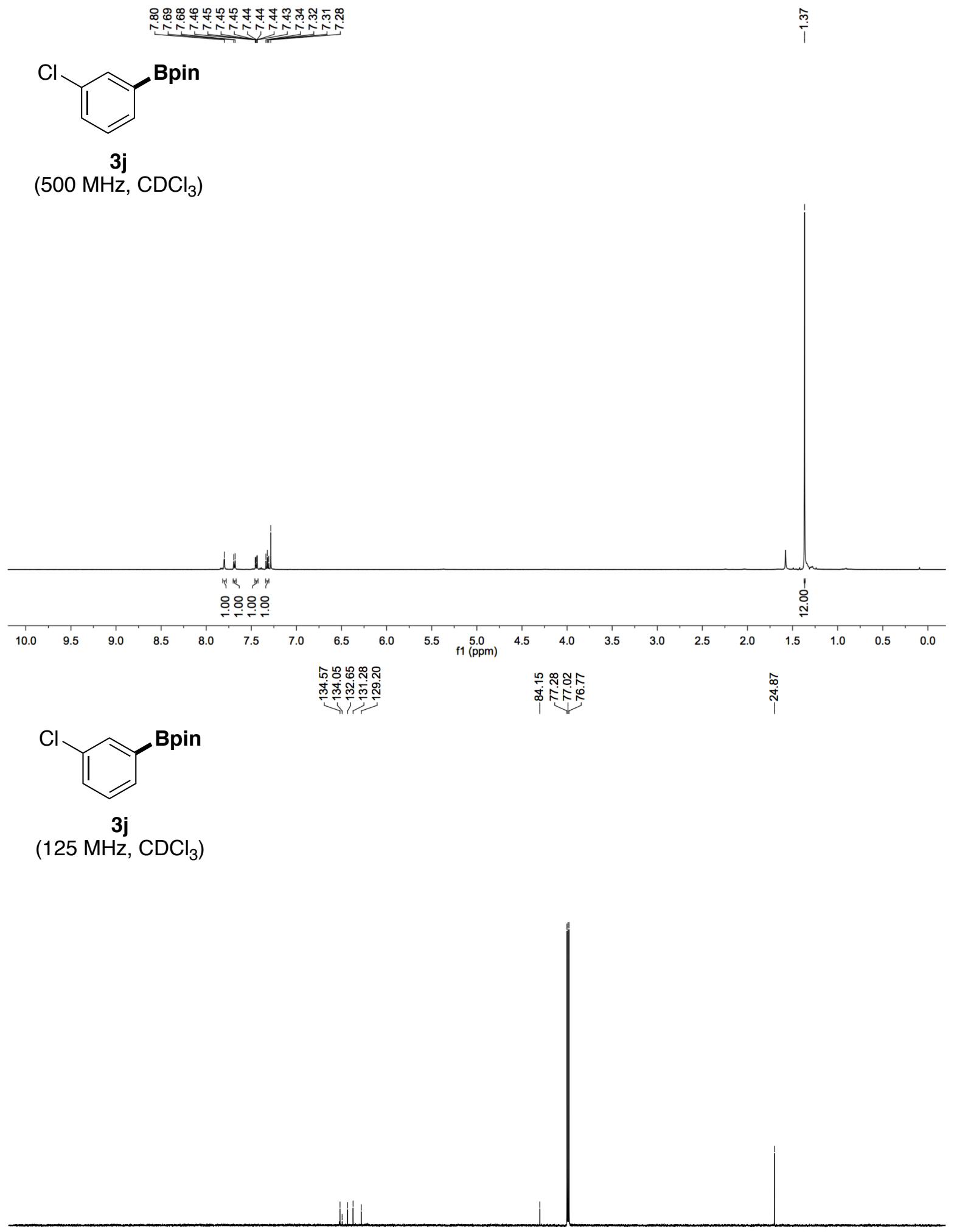

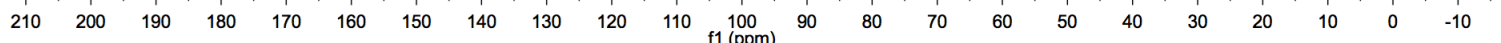




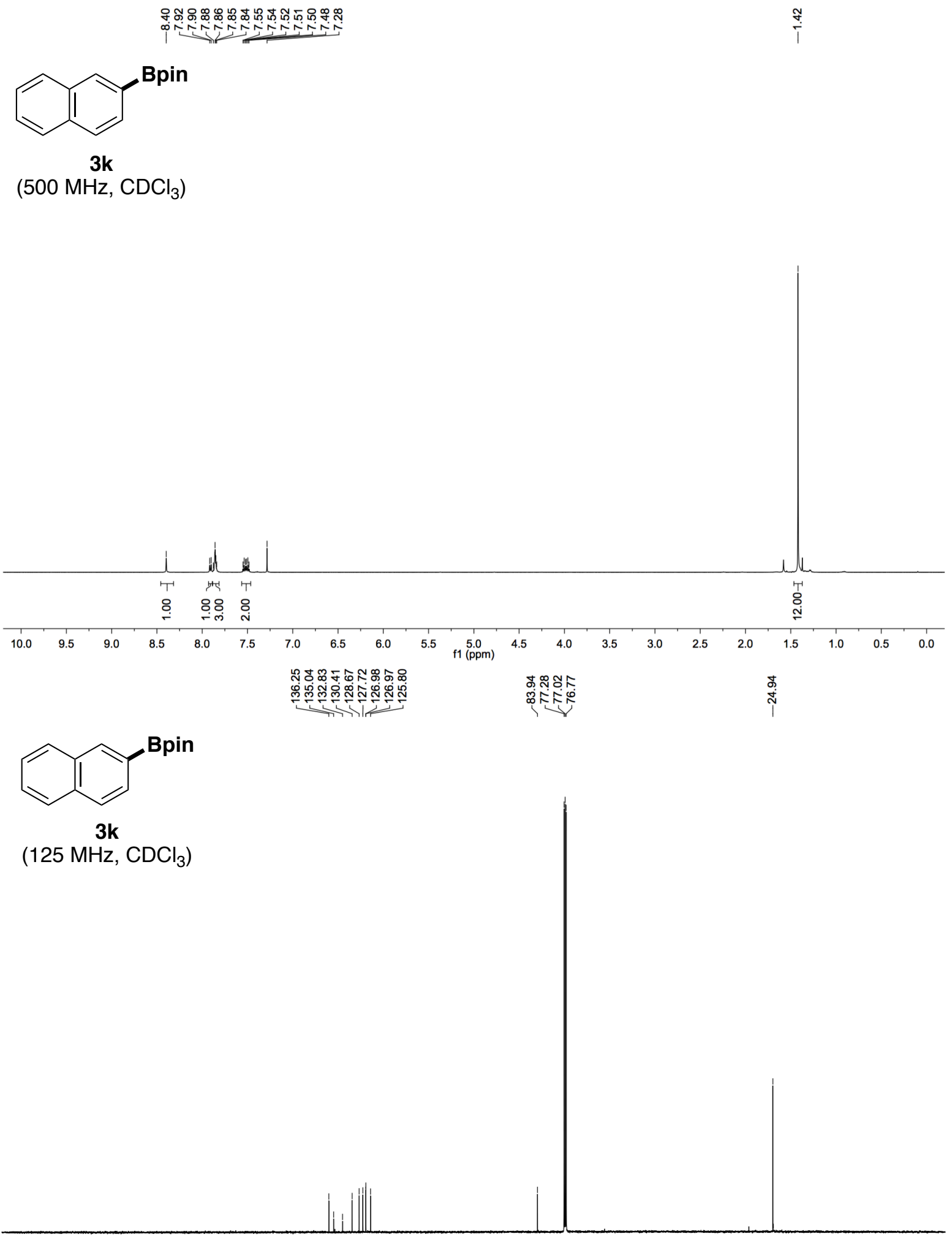

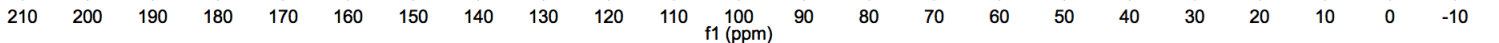



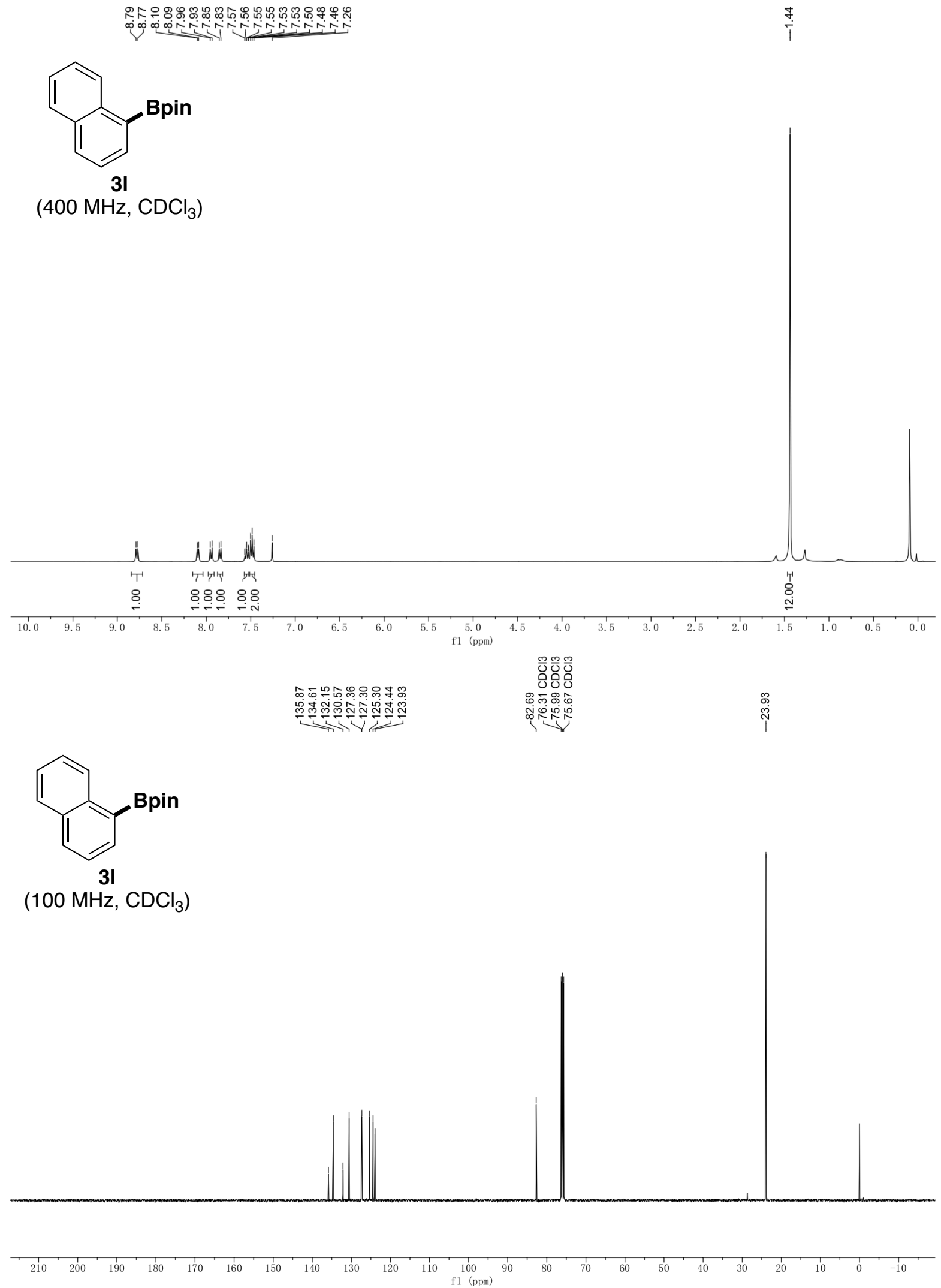


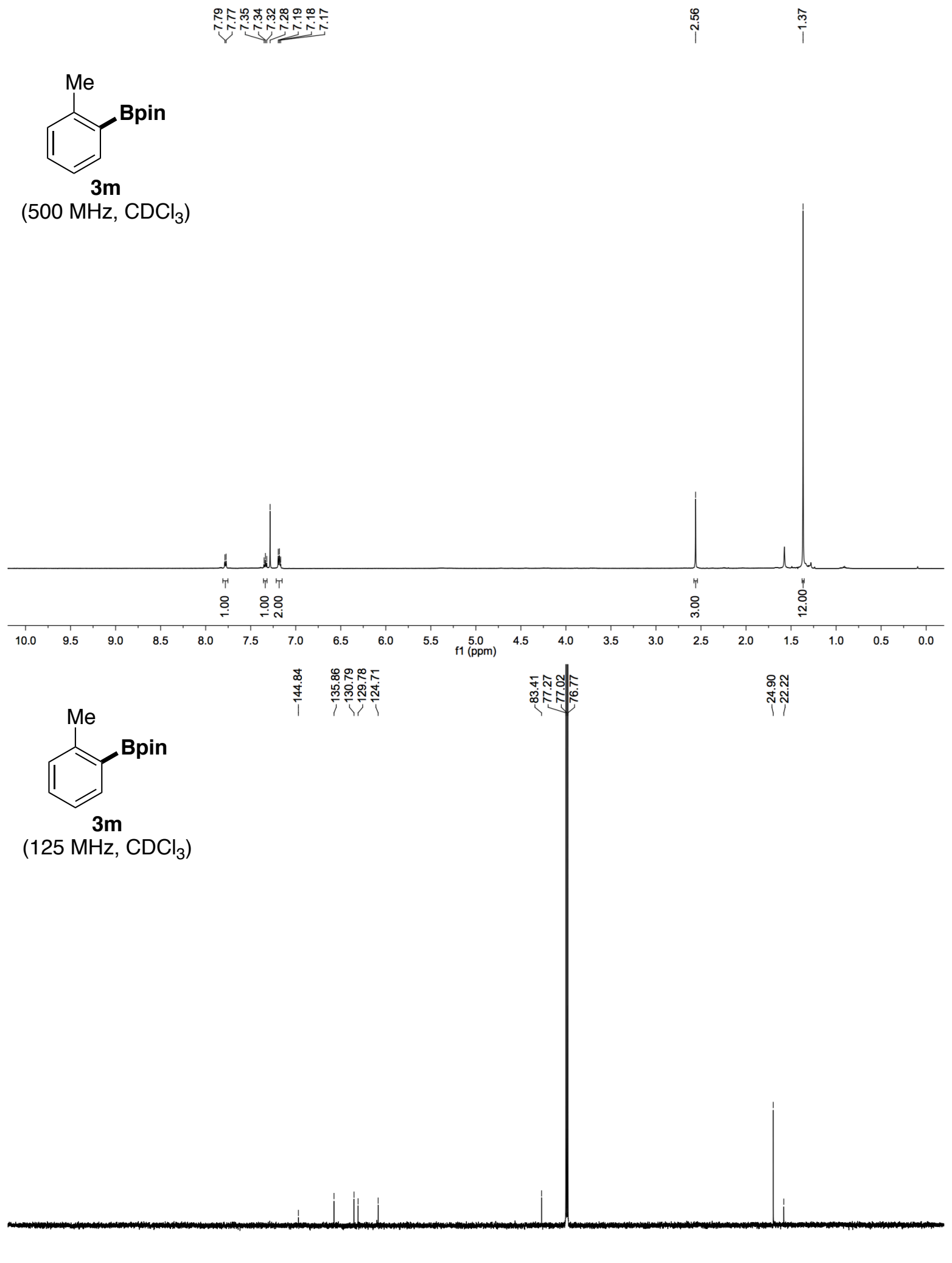

$\begin{array}{llllllllllllllllllllll}210 & 200 & 190 & 180 & 170 & 160 & 150 & 140 & 130 & 120 & 110 \underset{\mathrm{f} 1(\mathrm{ppm})}{100} & 90 & 80 & 70 & 60 & 50 & 40 & 30 & 20 & 10 & 0 & -10\end{array}$ 

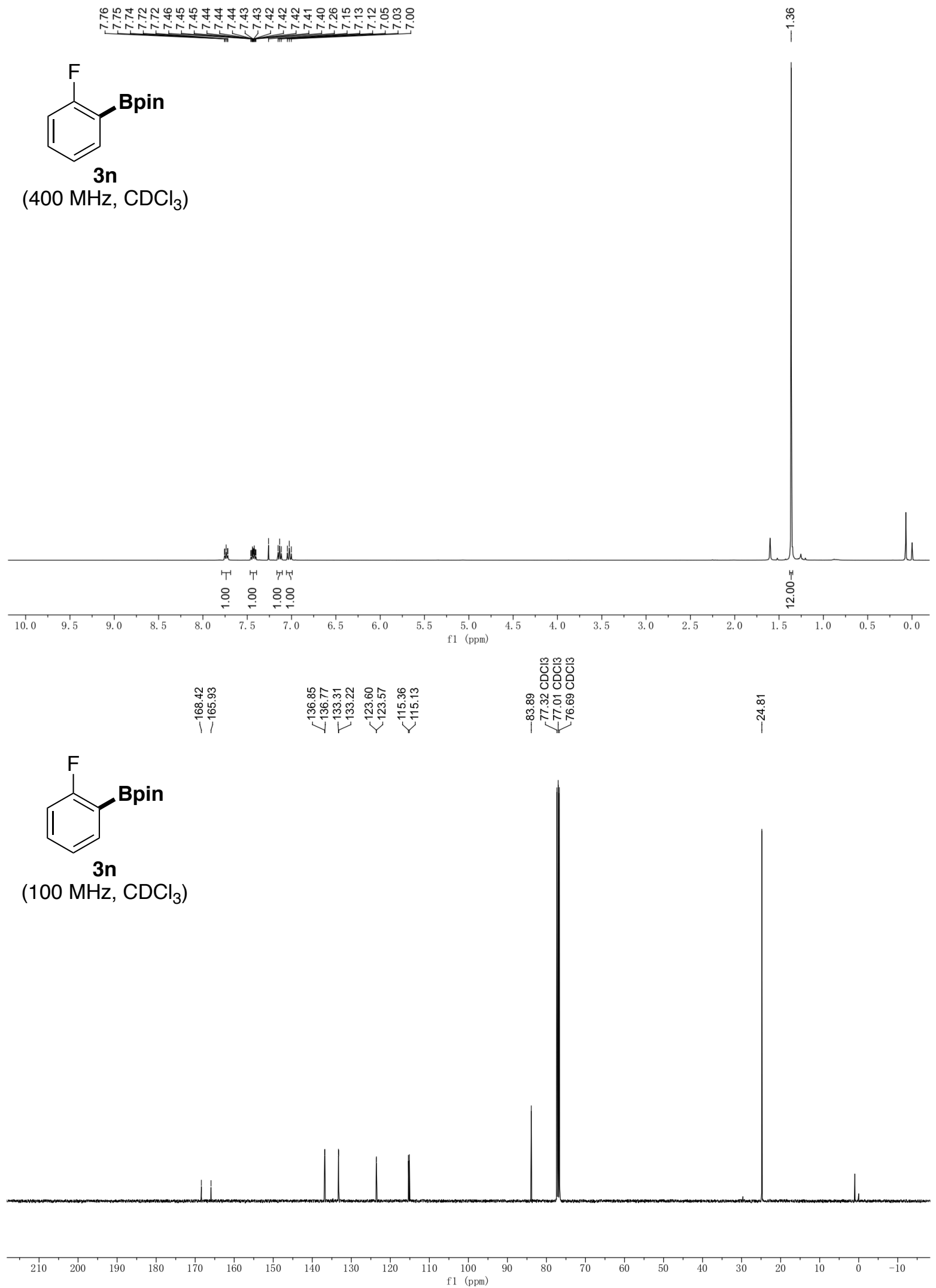
<smiles>Fc1ccccc1Br</smiles>

3n

(377 MHz, $\mathrm{CDCl}_{3}$ )

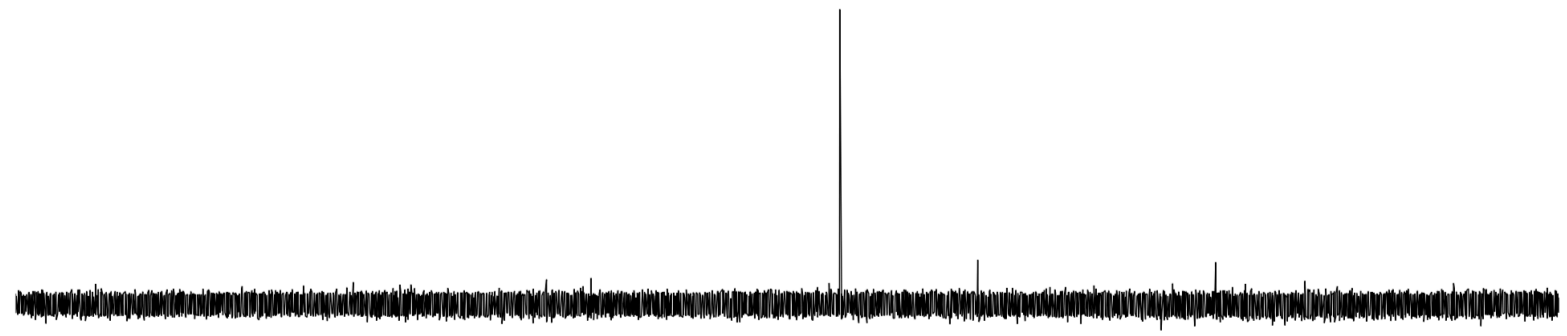

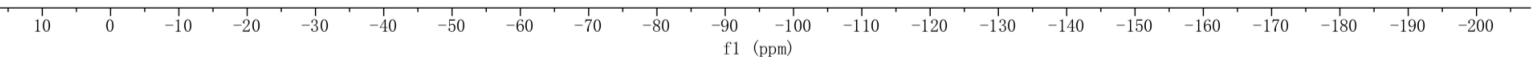



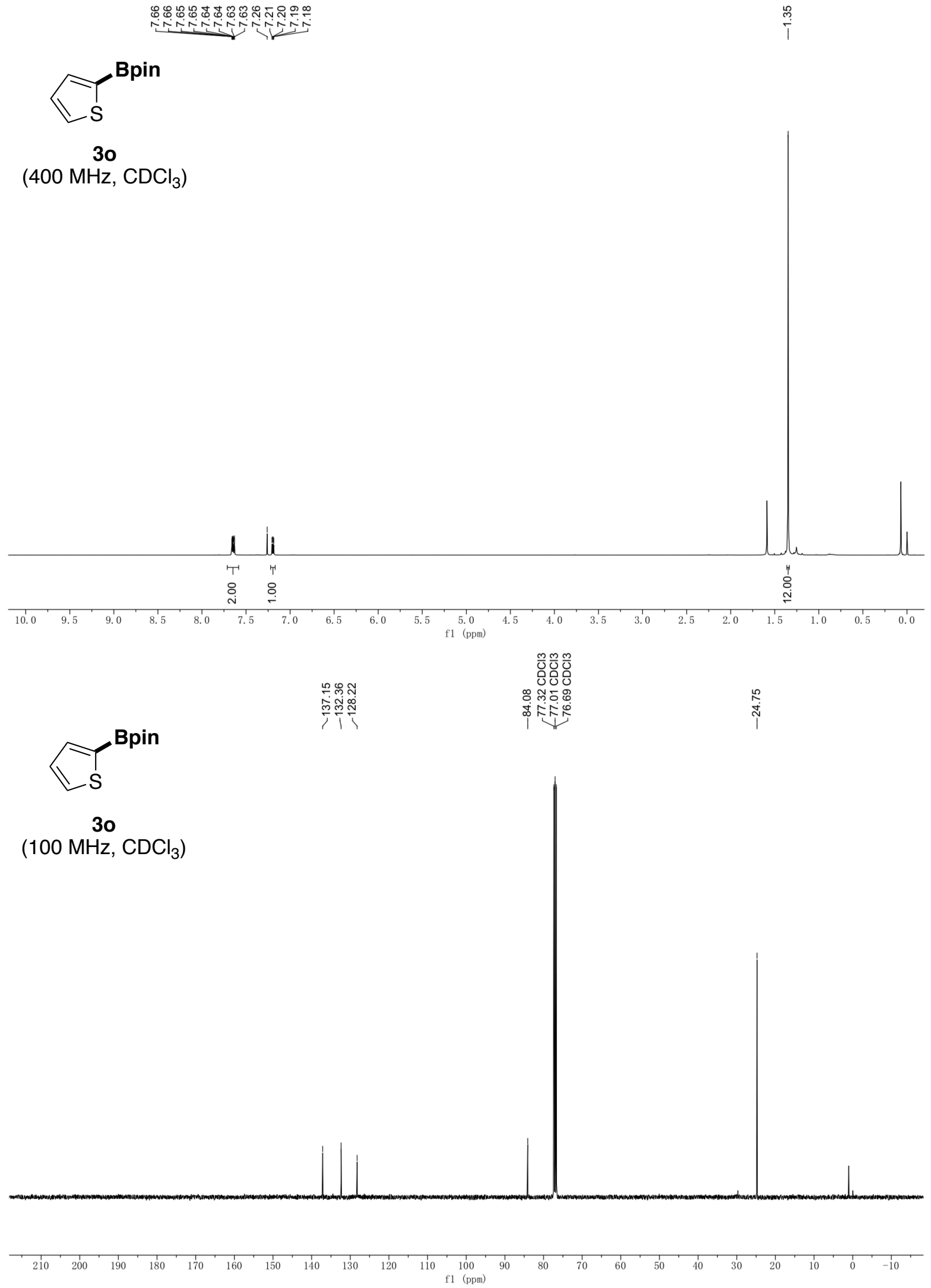

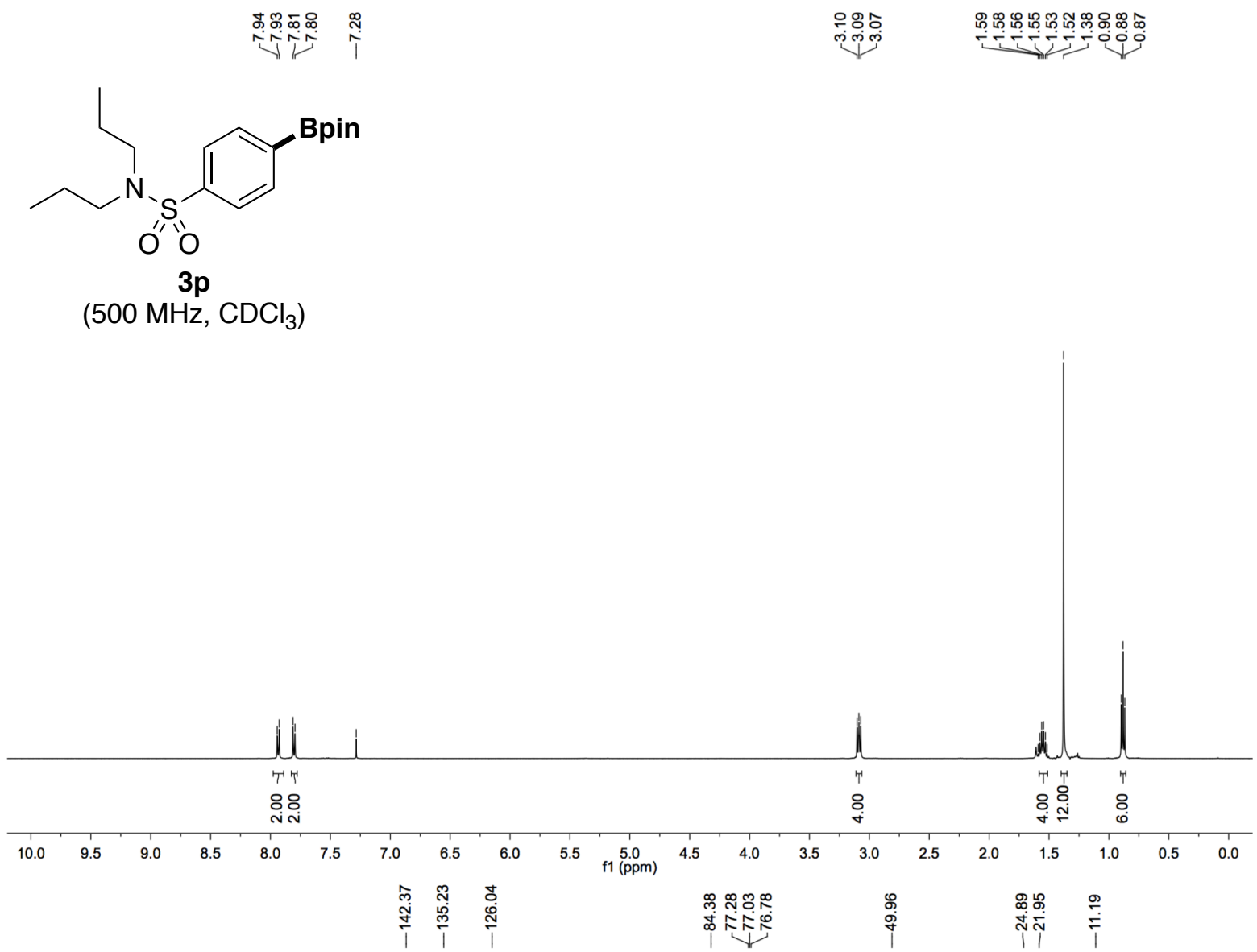<smiles>CCCN(CCC)S(=O)(=O)c1ccc(Cc2ccccc2)cc1</smiles>

$3 p$

(125 MHz, $\mathrm{CDCl}_{3}$ ) 

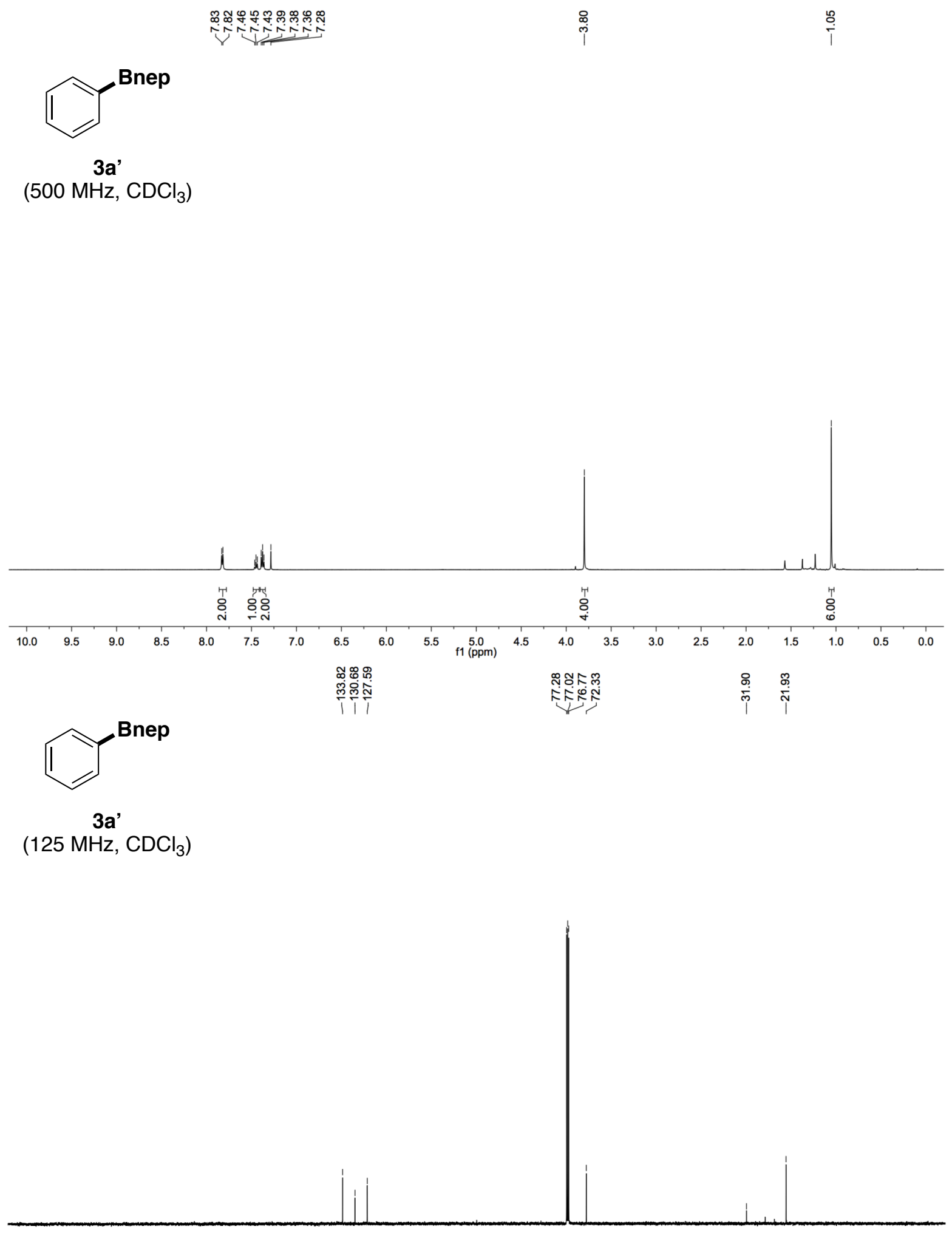

$\begin{array}{lllllllllllllllllllllllll}210 & 200 & 190 & 180 & 170 & 160 & 150 & 140 & 130 & 120 & 110 & 100 & 90 & 80 & 70 & 60 & 50 & 40 & 30 & 20 & 10 & 0 & -10\end{array}$ 

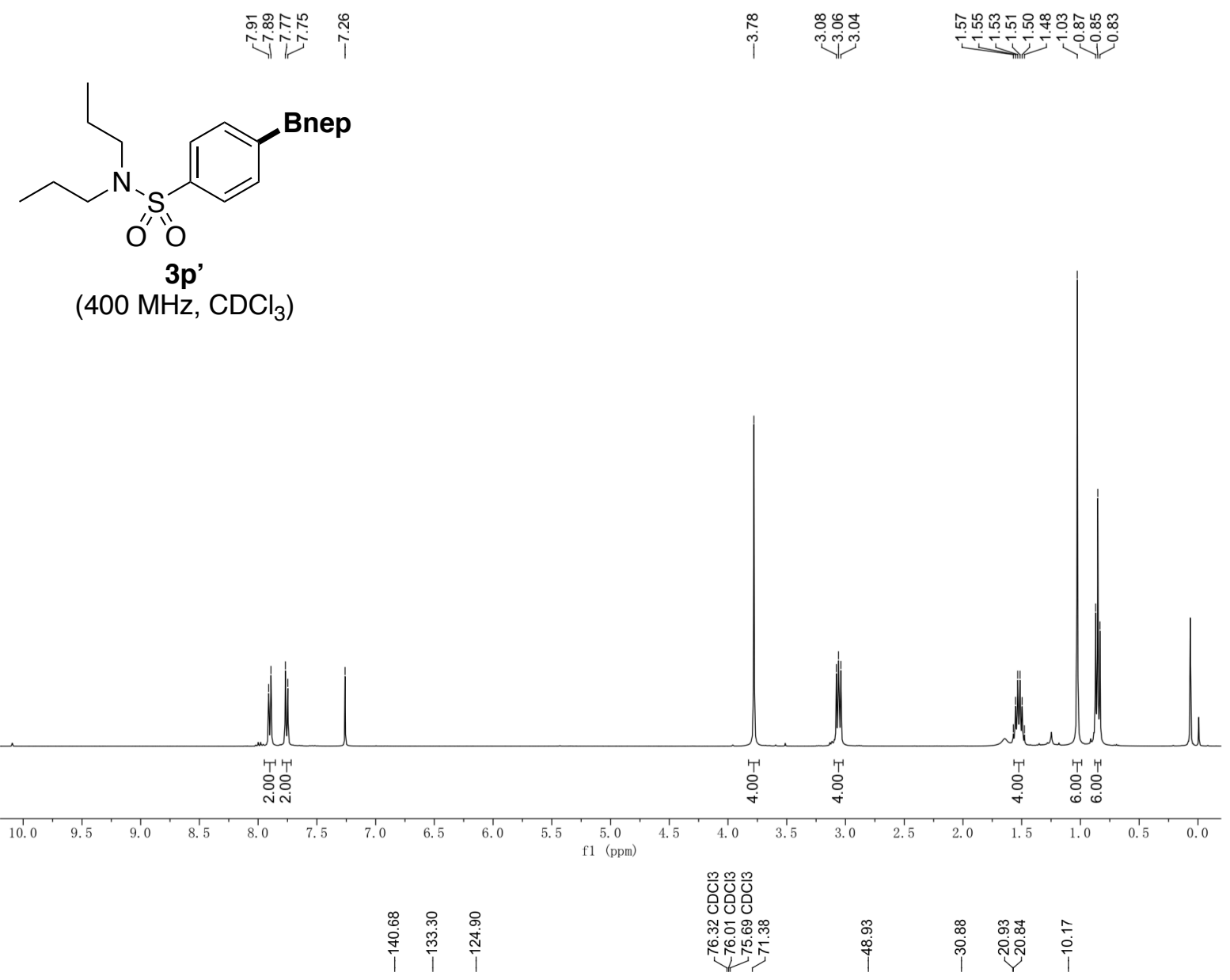<smiles>CCCN(CCC)S(=O)(=O)c1ccc(Br)cc1</smiles>

$3 p^{\prime}$

(100 MHz, $\mathrm{CDCl}_{3}$ ) 